\title{
Rietveld Quantitative Phase Analysis of OPC Clinkers, Cements and Hydration Products
}

\author{
Miguel A. G. Aranda,* Ángeles G. De la Torre \\ Departamento de Química Inorgánica, Cristalografía y Mineralogía \\ Universidad de Málaga \\ 29071 Málaga, Spain \\ email:g_aranda@uma.es
}

Laura León-Reina

Servicios Centrales de Investigación

Universidad de Málaga

29071 Málaga, Spain

\section{BRIEF INTRODUCTION}

It has been more than twenty years since the excellent volume of Reviews in Mineralogy dedicated to Modern Powder Diffraction was published (Bish and Post 1989). That volume contained a series of key articles ranging from the basic of powder diffraction to sample preparation and synchrotron and neutron powder diffraction. Within that volume, quantitative phase analysis was extensively discussed in a specific chapter (Snyder and Bish 1989). Snyder and Bish (1989) discussed the Reference Intensity Ratio approach (also known as Chung method), the method of standard additions (also known as spiking method) and the full patternfitting approach using both the Rietveld method and the observed patterns method. The reader is referred to that volume for the basics of powder diffraction, and to the specific chapter by Snyder and Bish (1989) for the history of quantitative phase analysis from powder diffraction and for a discussion or the early findings. Quantitative phase analysis by X-ray powder diffraction dates back to 1925 (Navias 1925). In this work, the amount of mullite obtained by firing selected clays (and a feldspar) was determined by the direct comparison of the intensities of two diffraction lines of the fired samples with those of pure mullite. The patterns were recorded on photographic negatives after an X-ray exposure of 165 hours (almost a week).

Quantitative phase analysis (QPA) from diffraction data can be obtained from a number of methods explained in classical books (Klug and Alexander 1974; Cullity 1978; Snyder and Bish 1989; Zevin and Kimmel 1995; Jenkins and Snyder 1996). However, it is now safe to say that QPA from powder diffraction data is nowadays mainly based on the Rietveld methodology (Rietveld 1969; Hill and Howard 1987; Bish and Howard 1988; Bish and Post 1993; Madsen and Scarlett 2008). Hence, the term Rietveld quantitative phase analysis (RQPA) has been coined. The advantages of using a full pattern-fitting over single peak(s) approaches are discussed in those papers and they will not be further addressed here. Hence, we will focus on RQPA. The readers should also be aware of two excellent articles which were the outcome of a round robin study on quantitative phase analysis by powder diffraction mainly using the Rietveld method (Madsen et al. 2001; Scarlett et al. 2002). These interlaboratory comparison studies made some indispensable recommendations for carrying out an accurate RQPA and included results concerning the influence of sample-related effects such as preferred orientation and microabsorption. However, it is also worth mentioning, that the key book entitled "The Rietveld Method" (Young 1993) does not contain a chapter on quantitative phase 
analysis. Furthermore, the key paper "Rietveld refinement guidelines" (McCusker et al. 1999), supported by the International Union of Crystallography, did not dedicate a section to RQPA.

On the other hand, building materials, such as ordinary Portland cements (OPCs), are very complex samples of worldwide importance, hence quantitative knowledge of their mineralogical composition is necessary to predict performances (Taylor 1997). Ultimately, the assemblage of crystalline phases, and not the bulk chemistry, determines cement features. In fact, the hydraulic properties of a mortar/concrete mainly depend on the cement mineralogical composition and its texture (Bentz 2008; Skibsted and Hall 2008; Scrivener and Nonat 2011).

The most widely used method of estimating the potential phase composition of Portland cement in cement plants is the Bogue calculation from its elemental analysis usually determined by X-Ray Fluorescence, XRF (Bogue 1929; Taylor 1989). However, it is well known that the phase abundance calculated by this indirect approach may be quite far from the true values. This is due mainly to three reasons: i) the four main clinker phases are solid solutions with compositions significantly different from the stoichiometric pure-phases; ii) there is no certainty of attaining equilibrium conditions (both in the kiln and for sure in the cooling process, Hong et al. 2001); iii) the presence of minor phases. As an alternative approach, RQPA allows a direct measurement of the phase content of cements. So, on-line systems for RQPA of clinkers and cements are becoming widespread. However, we will not deal here with on-line RQPA at cement plants. The reader is addressed to specific publications dealing with this subject including reproducible sample preparation, fast data acquisition and fast-and-robust data analysis (Moller 1998; Manias et al. 2001; Scarlett et al. 2001; Fullmann and Walenta 2003; Paul et al. 2004; Enders and Berger 2007; De la Torre et al. 2011).

Therefore, this review focuses on the use of RQPA for understanding OPC clinkers, cements and pastes, at central laboratories. It must be highlighted that a very recent review article has been dedicated to the application of the Rietveld method to the analysis of anhydrous cements (Le Saout et al. 2011). Furthermore, a second broad article dealing with direct determination of phases in OPCs by quantitative X-ray powder diffraction has also been reported (Stutzman 2011). Hereafter, cement nomenclature will be used, i.e., $\mathrm{C}=\mathrm{CaO}, \mathrm{S}=\mathrm{SiO}_{2}, \mathrm{~A}=\mathrm{Al}_{2} \mathrm{O}_{3}, \mathrm{~F}=$ $\mathrm{Fe}_{2} \mathrm{O}_{3}, \mathrm{M}=\mathrm{MgO}, \overline{\mathrm{S}}=\mathrm{SO}_{3}, \overline{\mathrm{C}}=\mathrm{CO}_{2}, \mathrm{H}=\mathrm{H}_{2} \mathrm{O}, \mathrm{K}=\mathrm{K}_{2} \mathrm{O}$ and $\mathrm{N}=\mathrm{Na}_{2} \mathrm{O}$. Hence, typical cement phase such as alite $\left(\mathrm{Ca}_{3} \mathrm{SiO}_{5}\right)$, belite $\left(\mathrm{Ca}_{2} \mathrm{SiO}_{4}\right)$, tricalcium aluminate $\left(\mathrm{Ca}_{3} \mathrm{Al}_{2} \mathrm{O}_{6}\right)$, calcium aluminoferrate $\left(\mathrm{Ca}_{4} \mathrm{Al}_{2} \mathrm{Fe}_{2} \mathrm{O}_{10}\right)$, gypsum $\left(\mathrm{Ca}_{2} \mathrm{SO}_{4} \cdot 2 \mathrm{H}_{2} \mathrm{O}\right)$ or calcite $\left(\mathrm{CaCO}_{3}\right)$ are abbreviated as $\mathrm{C}_{3} \mathrm{~S}, \mathrm{C}_{2} \mathrm{~S}, \mathrm{C}_{3} \mathrm{~A}, \mathrm{C}_{4} \mathrm{AF}, \mathrm{C} \overline{\mathrm{S}} \mathrm{H}_{2}$ and $\mathrm{C} \overline{\mathrm{C}}$, respectively. Most cement compounds are not pure stoichiometric phases but they may incorporate many ions as extensively discussed (Taylor 1997; Le Saout et al. 2011). In addition, AFm and AFt set of phases should be defined. AFm stands for the abbreviation for "alumina, ferric oxide, mono-sulfate" or " $\mathrm{Al}_{2} \mathrm{O}_{3}-\mathrm{Fe}_{2} \mathrm{O}_{3}$-mono", in the same way AFt stands for a similar abbreviation but "tri-sulfate" or " $\mathrm{Al}_{2} \mathrm{O}_{3}-\mathrm{Fe}_{2} \mathrm{O}_{3}$-tri". The AFm phase refers to a family of hydrated calcium aluminates based on the hydrocalumite structure, $\mathrm{Ca}_{4} \mathrm{Al}_{2}(\mathrm{OH})_{12} \cdot[\mathrm{Cl}(\mathrm{OH})] \cdot 6 \mathrm{H}_{2} \mathrm{O}$. The archetype AFm phase is $\mathrm{C}_{3} \mathrm{~A} \cdot \mathrm{CaSO}_{4} \cdot 12 \mathrm{H}_{2} \mathrm{O}$ or $\mathrm{Ca}_{4} \mathrm{Al}_{2}(\mathrm{OH})_{12} \cdot\left[\mathrm{SO}_{4}\right] \cdot 6 \mathrm{H}_{2} \mathrm{O}$, known as Kuzelite, but $\mathrm{Al}$ can be partly replaced by $\mathrm{Fe}$ and $\mathrm{SO}_{4}{ }^{2-}$ can be partly or fully replaced by $\mathrm{OH}^{-}, \mathrm{CO}_{3}{ }^{2-}$ and other anions (Pollmann 2006, Matschei et al. 2007a). The different hydration stages strongly influence the X-ray powder diffraction patterns (Pollmann 2007; Balonis and Glasser, 2009). By far the most common AFt phase is ettringite which has the following stoichiometry $\mathrm{C}_{3} \mathrm{~A} \cdot 3 \mathrm{CaSO}_{4} \cdot 32 \mathrm{H}_{2} \mathrm{O}$ that can also be written as $\mathrm{Ca}_{6} \mathrm{Al}_{2}\left(\mathrm{SO}_{4}\right)_{3}(\mathrm{OH})_{12} \cdot 26 \mathrm{H}_{2} \mathrm{O}$.

\section{THE RIETVELD METHOD}

Crystalline compounds have long range periodic order and its interaction with X-rays (or neutrons) yield powder diffraction patterns plenty of peaks/reflections. The position, height and even width of these reflections may be used to determine many aspects of the sample structure/ 
microstructure. The reader is referred to the two most recent books in "Powder Diffraction" to expand on that (Pecharsky and Zavalij 2005; Dinnebier and Billinge 2008). The Rietveld method is a technique devised by Hugo Rietveld in the late sixties (Rietveld 1967, 1969) for a deeper characterization of polycrystalline compounds by treating in a "better/different" way the powder diffraction patterns.

The very original contribution of the Rietveld method to powder diffraction was its conceptual breakthrough: "To use measured powder pattern intensities instead of reflection (peak) intensities." This conceptual breakthrough, together with the coming of computers, allowed to properly dealing with strongly overlapping reflections. The introduction of this technique was a significant step forward in the diffraction analysis of crystalline powder samples. The powder diffraction analysis at that moment worked with extracted reflection intensities which was a very serious difficulty in the case of overlapping reflections.

The Rietveld (whole-profile) method uses a least squares approach to optimize a theoretical line profile until it matches in the best possible way the measured sample powder diffraction profile (see Eqn. 1); where $S_{y}$ is the function to be minimized, $w_{i}$ is the statistical weight, and $y_{i}(\mathrm{obs})$ and $y_{i}(\mathrm{cal})$ are the observed and calculated powder diffraction intensities for the $i$-point of the powder pattern, respectively.

$$
S_{y}=\sum_{i} w_{i}\left|y_{i}(\mathrm{obs})-y_{i}(\mathrm{cal})\right|^{2}
$$

The calculated intensity, $y_{i}(\mathrm{cal})$, for each point of the powder pattern, $2 \theta_{i}$, is obtained as the sum of the contribution of all reflections $(k)$ which give intensity to that $i$-point above the background, $y_{b}\left(2 \theta_{i}\right)$, see Equation (2):

$$
y_{i}(\mathrm{cal})=y_{b}\left(2 \theta_{i}\right)+S_{\alpha} \sum_{k} m_{k}\left|F_{k}\right|^{2} h\left(2 \theta_{i}-2 \theta_{k}\right) L p\left(2 \theta_{i}\right) P_{k}
$$

where $S_{\alpha}$ is the scale factor for the pure crystalline $\alpha$-phase to be studied, $k$ stands for the reflections which contribute to that point of the pattern, $m_{k}$ is the multiplicity of that reflection, $F_{k}$ is the structure factor of that reflection, $h\left(2 \theta_{i}-2 \theta_{k}\right)$ is the function that distributes the intensity of that reflection in a given $2 \theta$ range, $\operatorname{Lp}\left(2 \theta_{i}\right)$ stands for the Lorentz and polarization correction, and $P_{k}$ stands for additional corrections that may be needed (preferred orientation, extinction, etc.).

Equation (2) may be extended to a sample containing $m$-crystalline phases, see Equation (3), by summing up the contribution of every crystalline phase.

$$
y_{i}(\mathrm{cal})=y_{b}\left(2 \theta_{i}\right)+\sum_{i=1}^{m} S_{i} \sum_{k} m_{k}\left|F_{k}\right|^{2} h\left(2 \theta_{i}-2 \theta_{k}\right) \operatorname{Lp}\left(2 \theta_{i}\right) P_{k}
$$

The Rietveld method was originally devised for the refinement of crystal and magnetic structures from powder neutron data. However, today the uses of the Rietveld method are numerous and help extracting the maximum information already present in a powder diffraction pattern. This information is listed just below and it must be highlighted that the Rietveld method is making a profound impact in every listed use as it increases the accuracy and precision of the extracted results. It can also be said that Hugo Rietveld did not envisage some of these uses including quantitative phase analysis (Rietveld 2010). From the position of the diffraction peaks: i) lattice parameters, ii) space group determination, iii) qualitative phase analysis (phase identification), and iv) macro-strain; from the intensities of the diffraction peaks: v) crystal (nuclear) structure (including atomic positions, occupation factors and atomic displacement parameters), vi) magnetic structure, vii) texture (preferred orientation), and viii) quantitative phase analysis; from the widths/shapes of the diffraction peaks: ix) micro-strains (mainly in solid solutions), and x) coherent diffraction domain size(s). 
In this review article, we will focus on the viiith-application, quantitative phase analysis. We address the reader to some selected books and papers for a deeper insight of the role of the Rietveld method in the remaining applications (Young 1993; McCusker et al. 1999; David et al. 2002; Shin et al. 2002; Fitzpatrick and Lodini 2003; Balzar et al. 2004; Pecharsky and Zavalij 2005; Kaduk 2007a,b; Dinnebier and Billinge 2008; David and Shankland 2008; Soleimanian and Aghdaee 2008; Markvardsen et al. 2008). Finally, new ways of learning are being explored. In addition to books, papers and training in laboratories with proven experience, other methods are emerging. If the reader is keen of using internet-distributed audio/visual material, then the following references are a good starting point (Toby 2007, 2010).

\section{General issues}

For a successful Rietveld quantitative phase analysis, several steps have to be fulfilled. Initially, sample has to be properly prepared and this will depend upon the nature of the sample itself and the diffractometer where the data will be taken. This will be briefly discussed in a later section. Secondly, the diffractometer should be well aligned and maintained. Different optical configurations are possible in modern diffractometers and the optimal set-up should be used. Under these two pre-requisites, a good powder diffraction pattern may be taken and RQPA can be carried out. It must be highlighted that the results of any analysis cannot be better than the raw data. Therefore, a lot of care is needed in these two initial steps in order not to spend/waste a lot of time in data analysis/evaluation without conclusive results.

Once good powder diffraction data have been taken, a third step follows: qualitative phase analysis. Every crystalline phase in the sample should be identified. This is easy to say but sometimes quite complex to fulfill. The strong peak overlapping in the diffraction patterns does not allow to conclusively determining all phases present in some cases. Then a possible strategy follows, we compute the RQPA with the phases which are clearly present in the pattern and, from the net intensity in the difference curve, the remaining low-content phases are determined. Alternatively, a trial-and-error method can be used. In addition to the main, clearly-observed phases, dubious phases are added to the Rietveld calculation and its absence/ presence can be individually estimated.

In any case, when the main (all) phases are identified, the fourth step is to carry out the RQPA with the appropriate software. A full list, and discussion, of the programs available for this task is out of the scope of this paper. However, we can suggest the ccp14 web site for a list of Rietveld programs (http://www.ccp14.ac.uk/solution/rietveld_software/index.html) and mention that GSAS (Larson and von Dreele 1994; Toby 2001) and FULLPROF (RodriguezCarvajal 1993; Roisnel and Rodriguez-Carvajal 2001) are the widest used packages. Many other packages can also be used for RQPA and we underline just a few: BGMN, SIROQUANT, TOPAS and HighScore Plus. In any case, in addition to the raw data, any Rietveld program needs a control file to execute the refinements. In this control file, the crystal structures of the different components must be included. The fit is carried out by optimizing all appropriate variables such as: i) scale factor of every crystalline phase; ii) background parameters for the chosen function; iii) unit cell parameters for every crystalline phase; iv) peak shape parameters for every computed phase; and finally, v) correction parameters which may be phase-dependent (such as preferred orientation, extinction, etc.) or pattern-dependent (zero-shift, absorption correction when working in transmission geometry, etc.). Usually, for RQPA the structural descriptions (atomic positional parameters, atomic displacement parameters and occupation factors) are not optimized but kept as reported in the structural studies.

The RQPA method does not require calibration curve or internal standard. However, the crystal structures of all crystalline constituents must be known. This is a prerequisite as the process consists of the comparison between the measured and the calculated patterns (the calculated pattern being computed from the crystal structures). 
The application of RQPA to clinkers/cements/pastes is not straightforward for the following reasons: i) there are many phases, usually more than five, which increases the diffraction peak overlapping and so the correlations; ii) each phase has its own mass absorption coefficient which may yield the microabsorption problem (see below); iii) the small mean penetration depth of X-rays $(\sim 30 \mu \mathrm{m}$ for $\mathrm{Cu} \mathrm{K \alpha}, 1.54 \AA)$ implies that only a thin layer is analyzed in the Bragg-Brentano $\theta / 2 \theta$ geometry which may lead to poor particle statistics; iv) some phases, for instance alite or gypsum crystallize as plaques which show preferred orientation and so increases the errors; v) phases can crystallize as several polymorphs that must be identified a priori; vi) the diffraction peak broadening for some phases may be anisotropic and it must be properly model; and vii) the atomic impurities inside each phase are not known and their scale factors are computed for ideal/stoichiometric phases. In any case, this method has several advantages over other methods based on powder diffraction and other technologies (microscopy, thermal analysis, etc.). A comparison between RQPA results and those obtained with alternative/complementary technologies will be given below.

The direct output of the RQPA is a set of scale factors, one for every crystalline phase within the mixture with computed crystal structures. In addition, several other parameters may be of interest: i) unit cell parameters (to have an idea of the existence of solid solutions); ii) preferred orientation of some phases (to have an insight of the particle shapes of these phases); iii) peak shape widths to know about the microstructures. The key transformation of the phase scale factors to phase contents is discussed in a section below. However, it must be highlighted that the best available structural description should be used in order to extract the best possible scale factor value for every phase. This is evaluated by the flatness of the difference curve and also by obtaining low Rietveld-disagreement indices (R-factors). However, the lowest $\mathrm{R}$-factors may also be obtained for wrong analysis. So, it is important to optimize those parameters that allow their minimization without excessive correlations. It is also important to understand the definitions for R-factors which are discussed in standard papers (Young 1993; McCusker et al. 1999). However, a much personal view has been reported (Toby 2006) which was mainly dedicated to the refinement of crystal structures but some concerns and discussions are of overall interest.

\section{Structural description of the phases present in OPC materials}

The main clinker phases are alite, belite and aluminate in white Portland clinkers and also ferrite in grey Portland clinkers. In addition several other minor phases may be present: lime, periclase, arcanite, aphthitalite and others, see Table 1. An excellent review about the phases present in OPC clinkers has been very recently published (Le Saout et al. 2011). We want to draw the attention that several issues are discussed in that paper including the selection of the alite polymorph, the implications of the Fe/Al ratio in ferrite quantification, and the consequences of the solid solution existence in most clinker phases (small change in the structure factors and densities of the analyzed phases).

Portland cements are fabricated by adding a setting regulator to the clinker. The sulfate phases added for this purpose may be gypsum $\left(\mathrm{CaSO}_{4} \cdot 2 \mathrm{H}_{2} \mathrm{O}\right)$, hemihydrate $\left(\mathrm{CaSO}_{4} \cdot \frac{1}{2} \mathrm{H}_{2} \mathrm{O}\right)$ also known as bassanite or anhydrite $\left(\mathrm{CaSO}_{4}\right)$. Different Portland cements may have different additions, for instance calcite $\left(\mathrm{CaCO}_{3}\right)$ or quartz $\left(\mathrm{SiO}_{2}\right)$. Additionally, other highly-amorphous materials may be added for blended cement and concrete production such as blast furnace slag (BFS), pulverized fly ash (PFA) or pozzonale minerals. It must be kept in mind that these additions also contain some crystalline phases (for instance mullite or hematite) that must be quantified in blended cements. Table 2 gives a list of additional phases that may be present in (blended) OPC cements.

New phases appear during hydration of OPC cements. Table 3 lists additional (hydrated) phases that may be present in Portland cement pastes. It should be noted that a review of 


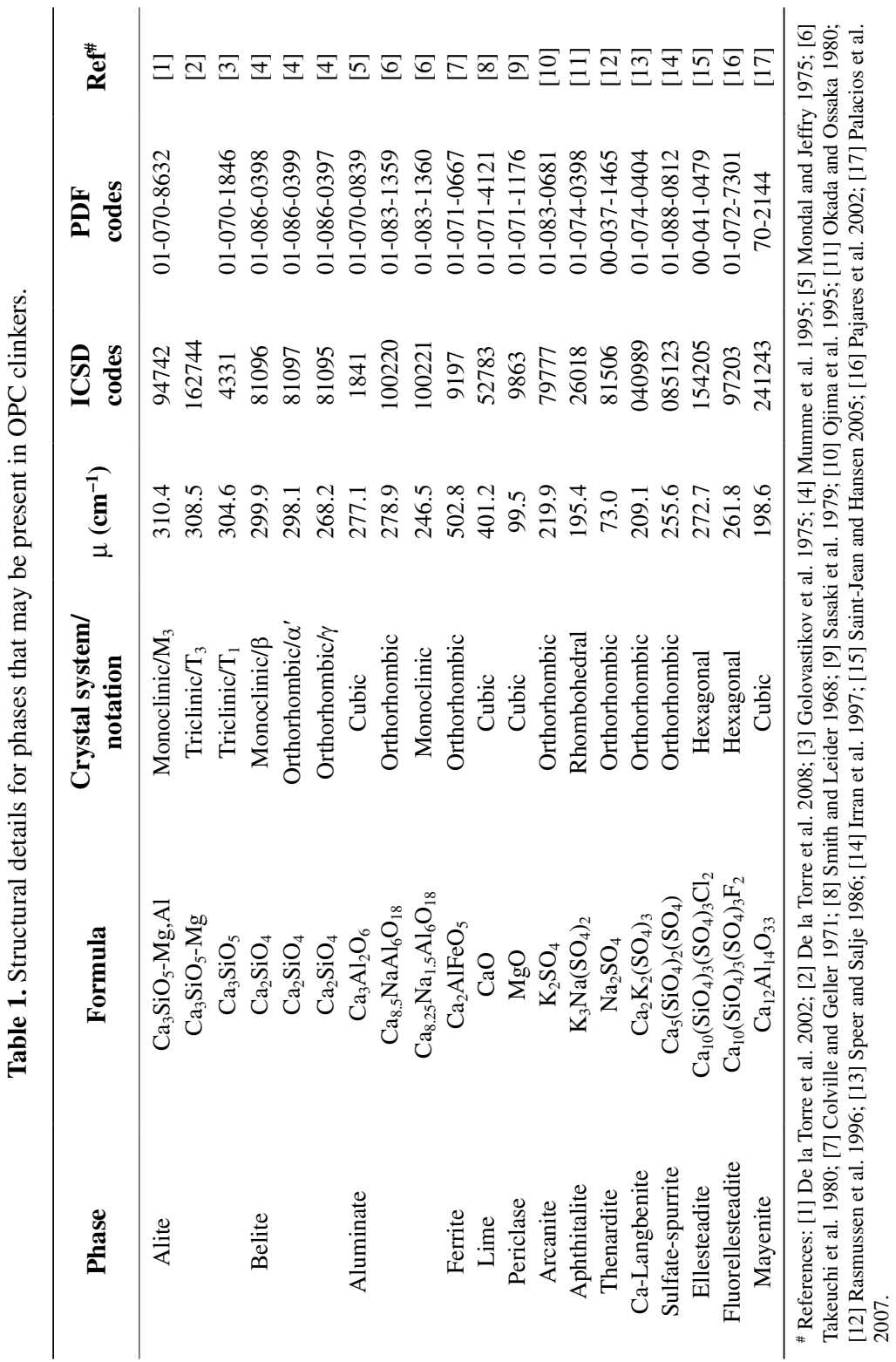




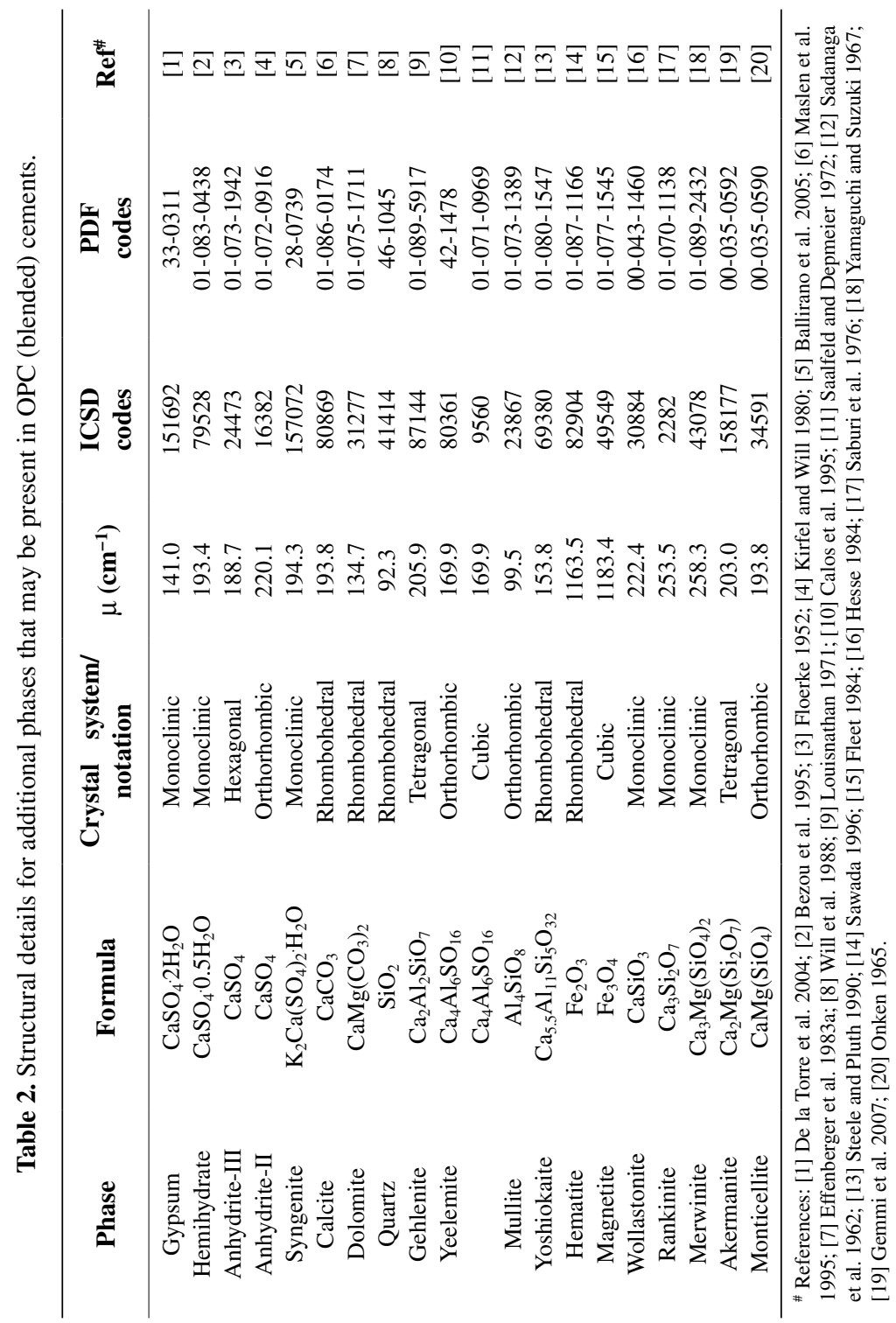




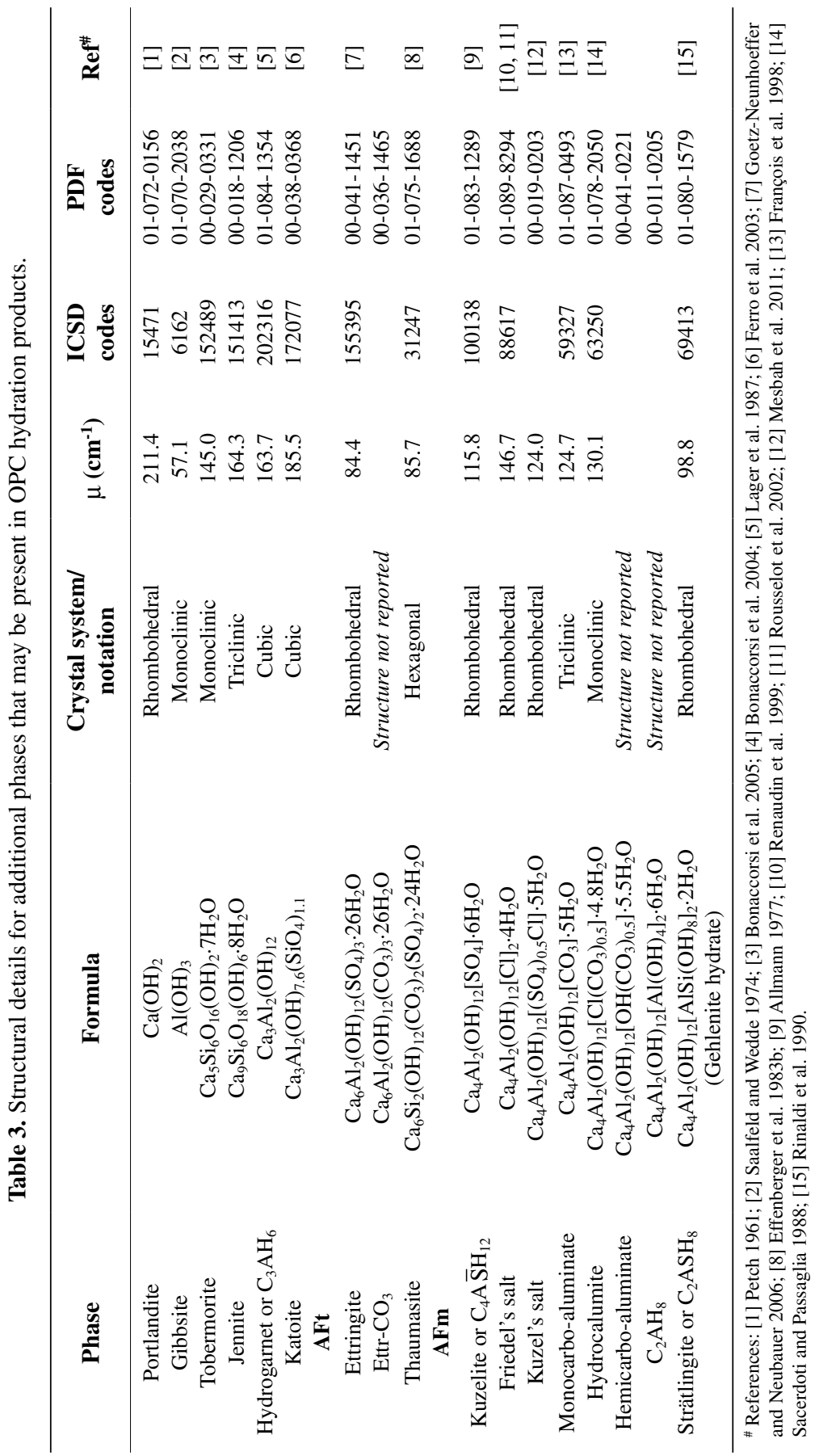


calcium silicate hydrates has been reported (Richardson 2008). Furthermore, the reader is also referred to an excellent review dealing with the density of cement phases including those of AFm and other hydrates (Balonis and Glasser 2009). The mineralogy (phases) of the hydrates compounds may depend upon the additions in blended cements (Matschei and Glasser 2010) and this should be taken into account.

\section{Whole-pattern quantitative phase analysis approaches}

As stated above, conventional RQPA requires all crystal structures to be known. There are alternative whole-pattern quantitative phase analysis methods for crystalline phases with unknown structures (Smith et al. 1987; Taylor and Zhu 1992; Scarlett and Madsen 2006) however these approaches will not be discussed/reviewed here.

The output of a RQPA study is a set of $m$-crystalline phase scale factors, $\Sigma_{m} S_{\alpha}$, for a sample with $m$-crystalline phases. A phase scale factor, $S_{\alpha}$, is related to the phase weight content, $W_{\alpha}$, by Equation (4) (Hill and Howard 1987; Bish and Howard 1988)

$$
S_{\alpha}=\mathrm{K}_{e}\left(\frac{W_{\alpha}}{\rho_{\alpha} V_{\alpha}^{2} \mu_{s}}\right)
$$

where $\mathrm{K}_{e}$ is a constant which depends on the diffractometer operation conditions, $\rho_{\alpha}$ is the crystallographic density of the $\alpha$-phase, $V_{\alpha}$ is the unit cell volume of $\alpha$-phase, and $\mu_{s}$ is the sample mass absorption coefficient. Equation (4) can be rewritten as given in Equation (5):

$$
S_{\alpha}=\mathrm{K}_{e}\left(\frac{W_{\alpha}}{(Z M V)_{\alpha} \mu_{s}}\right)
$$

where instead of using $\rho_{\alpha}$, the relation between $S_{\alpha}$ and $W_{\alpha}$ is based on the " $Z M V$ " term with $Z$ being the number of chemical units/formulas within the unit cell, $M$ being the molecular mass of the chemical formula, and $V$ the unit cell volume. Once the crystal structure is known, the " $Z M V$ " term is known. In any case, the parameter to be extracted, $W_{\alpha}$, depends on the phase scale factor, $S_{\alpha}$, but also on $\mathrm{K}_{e}$ and $\mu_{s}$. Unfortunately, these two variables are not known and they cannot be derived from the powder diffraction pattern of the sample under study.

Currently, there are three main ways to derive the phase content, $W_{\alpha}$, from the Rietveld refined scale factor, $S_{\alpha}$. These three methods are based on different mathematical approaches and they have different experimental complexities. They will be treated in detail just below.

I) Normalization to full crystalline phase content method. The simplest approach is the approximation that the sample is composed only of crystalline phases with known structures. These crystal structures are incorporated into the control file, and it was already shown (Hill and Howard 1987) that the weight fraction of $\alpha$-phase, for a $m$-crystalline phase mixture, may be given by Equation (6):

$$
W_{\alpha}=\frac{S_{\alpha}(Z M V)_{\alpha}}{\sum_{i=1}^{m} S_{i}(Z M V)_{i}}
$$

The use of Equation (6) in RQPA eliminates the need to measure the instrument calibration constant, $\mathrm{K}_{e}$, and the sample mass absorption coefficient, $\mu_{s}$. However, the method normalizes the sum of the analyzed weight fractions to 1.0. Thus, if the sample contains amorphous phases, and/or some amounts of unaccounted for crystalline phases, the analyzed weight fractions will be overestimated.

This approach is by far the most widely used method in RQPA and also in RQPA of OPCs. However, it must be highlighted that the resulting weight fractions are only accurate if the 
amount of unaccounted crystalline phases and amorphous content are very small (negligible) which may be not the case in anhydrous OPCs and for sure is not the case in OPC pastes.

II) Internal standard method. A second, more experimentally-demanding, approach is to mix the sample with a crystalline standard in a known amount, $W_{s t}$ (also known as spiking method). This standard must be free of amorphous content or at least its non-diffracting content must be known. This (artificial) mixture must be homogenized as the particles should be randomly arranged. Under these considerations, Equation (7) is fulfilled, where $S_{s t}$ is the Rietveld scale factor of the standard in the artificial mixture (Hill and Howard 1987):

$$
W_{\alpha}=W_{s t} \frac{S_{\alpha}(Z M V)_{\alpha}}{S_{s t}(Z M V)_{s t}}
$$

The addition of the standard dilutes the crystalline phases in the sample. This may be quite problematic for low-content phases. A procedure for Rietveld quantitative amorphous content analysis was outlined, in which the effects of systematic errors in the powder patterns were studied (De la Torre et al. 2001a). The approach requires two powder patterns to be collected but it minimizes the errors. Firstly, a powder pattern of the sample of interest is collected and the crystalline phase contents are determined as stated in the previous section (normalized to a $100 \%$ of crystalline phases). A second pattern is collected for the sample mixed with the internal standard. The weight fraction added of the internal standard is known, $W_{s t}$, as it was weighed. The RQPA gives an overestimated value of this content, $R_{s t}$, due to the presence of amorphous phase(s), misfitting problems of the analyzed crystalline phases, and because some crystalline phases may not be included in the control file due to several reasons (its crystal structure is not known, the phase was not identified, etc.). This overall content is hereinafter

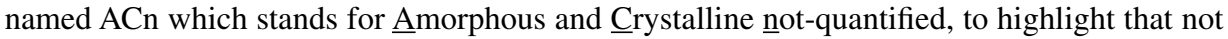
only an amorphous fraction but any not-computed crystalline phase and any misfit problem (for instance the lack of an adequate structural description for a given phase) may contribute to this number. The method derives the (overall) ACn content of the sample from the small overestimation of an internal crystalline standard, Equation (8) (De la Torre et al. 2001a):

$$
\mathrm{ACn}=\frac{1-\left(W_{s t} / R_{s t}\right)}{\left(100-W_{s t}\right)} \times 10^{4}(\mathrm{wt} \%)
$$

For this second refinement, the phase ratios between the crystalline phases in the sample may be kept fixed to the values obtained in the first fit and only the fraction of the added standard is optimized. Under these conditions, the overall ACn content is derived and this is applied to the weight fractions determined in the first fit to place them in an absolute scale. The errors associated to this approach and the optimum amount of standard has been recently discussed (Westphal et al. 2009). Finally, NIST standard reference material (SRM) 676a, corundum $\left(\alpha-\mathrm{Al}_{2} \mathrm{O}_{3}\right)$ powder, has been certified to have a phase purity of $99.02 \% \pm 1.11 \%(95 \%$ confidence interval) by RQPA against a suitable primary standard (powder silicon carefully prepared from a single crystal). This novel certification method permits quantification of amorphous content for any sample of interest by this spiking method (Cline et al. 2011). This methodology has been applied to anhydrous OPC and also to pastes. However, the addition of an internal standard may alter the OPC hydration reactions and dilutes the phases in the pastes.

III) External standard method (G-factor approach). To avoid complications that may arise from mixing an internal standard with the sample, it is possible to use an external standard method. This approach requires the recording of two patterns in identical diffractometer configuration/conditions for Bragg-Brentano $\theta / 2 \theta$ reflection geometry. The method was proposed some time ago (O'Connor and Raven 1988) and very recently applied to anhydrous cements (Jansen et al. 2011a) and organic mixtures (Schreyer et al. 2011). This method 
consists in determining the diffractometer constant, $\mathrm{K}_{e}$, with an appropriate standard (for instance silicon powder from Si-single crystal), see Equation (9), derived from Equation (4):

$$
\mathrm{G}=\mathrm{K}_{e}=S_{s t} \frac{\rho_{s t} V_{s t}^{2} \mu_{s t}}{W_{s t}}
$$

where $S_{s t}$ is the Rietveld scale factor of the (external) standard, $\rho_{s t}$ corresponds to the density of the standard, $V_{s t}$ is the unit cell volume of the standard, $W_{s t}$ is the weight fraction of the standard (ideally $100 \mathrm{wt} \%$ ) in the external standard pattern, and $\mu_{\mathrm{st}}$ is the mass attenuation coefficient of the standard. This method is also known as G-method as the standard allows to calculate the G-factor of the diffractometer in the operating conditions.

The calculated G-factor represents a calibration factor for the whole experimental setup and comprises the diffractometer used, radiation, optics, and all data acquisition conditions, (e.g., detector configuration, integration time, etc.). This G-factor is used to determine the mass concentration of each phase of the sample under study using Equation (10):

$$
W_{\alpha}=S_{\alpha} \frac{\rho_{\alpha} V_{\alpha}^{2} \mu_{s}}{G}
$$

This method allows determining the absolute weight fractions by using a diffractometer constant that must be previously determined. However, the mass attenuation coefficient of the sample is needed, $\mu_{s}$. This must be independently determined, and the most common way to obtain it, in cements, it is by X-ray fluorescence spectrometry (Jansen et al. 2011a). This methodology has been applied to anhydrous OPCs (Jansen et al. 2011a) and to OPC pastes (Jansen et al. 2012a,b). From Equation (10), it is clear that the weight fractions of all computed phases within the control file do not need to add up to $100 \mathrm{wt} \%$. From the difference between $100 \mathrm{wt} \%$ and the sum of the crystalline phase contents, an overall unaccounted/left-out weight percentage, ACn, can be derived. In any case, the external standard method is experimentally more demanding but it may have the brightest future for the study of hydration reactions. This sentence is based on the lack of need of spiking an internal standard. The addition of an internal standard is a very important drawback in hydration reaction studies since not only dilutes the phases in the sample but it may also interfere with the hydration reactions.

\section{SAMPLE PREPARATION AND DATA COLLECTION}

The preparation of samples for laboratory X-ray powder diffraction (LXRPD) is the crucial first step for a good quantitative analysis (Jenkins et al. 1996; Bish and Reynolds 1989; Buhrke et al. 1998). In order to extract the maximum (accurate) information from a powder pattern, two parameters have to be carefully controlled: i) the positions of the diffraction maxima should be at the right place, which means good diffractometer alignment/maintenance and good sample mounting practice; and ii) the peak intensities should be those expected from the crystal structure and phase assemblage, which means that a sufficiently large number of crystallites contributing to each reflection of every phase should be bathed by the X-rays. It is necessary to obtain diffraction peaks of reproducible intensity without altering the sample or inducing too much preferred orientation. The particle statistics is of the outmost importance in quantitative studies (Elton and Salt 1996; Whitfield and Mitchell 2009).

For $\mathrm{CuK} \alpha$ radiation in Brag-Brentano configuration, the relative standard deviation of the measured intensity due to particle statistics is less than a few percent when the particle size is smaller than $5 \mu \mathrm{m}$; however, the statistical error increases rapidly as the particle size is bigger than about $10 \mu \mathrm{m}$ (Smith 1992; Jenkins et al. 1996). For OPC samples where alite has usually particles much larger than that, this is a very serious problem. Severe grinding of the 
sample can be performed in order to reduce the average alite particle sizes to values close to $5 \mu \mathrm{m}$, however this treatment may alter the sample as partial amorphization may take place. Alternatively, rotating a flat-plate sample in its own diffracting plane does not help to reduce the prefer orientation effect but increases the reproducibility of the recorded intensities. Hence, samples with large particle sizes should be measured in the rotating stage and this recording setup is strongly recommended for Rietveld studies (McCusker et al. 1999). Furthermore, rotating the sample should be compulsory for RQPA of OPC samples.

If milling is necessary, then the addition of a milling agent (e.g., n-propyl alcohol or acetone) is recommended as this significantly increases the efficiency of grinding by uniformly reducing the particle size of the hard materials, without overgrinding the softer ones (Bish and Reynolds 1989). Extensive grinding may lead to the transformation of gypsum into bassanite (or even anhydrite) and even the amorphization of sulfate phases (Fullmann and Walenta 2003; Enders 2005). Milling OPC materials usually does not help to avoid microabsorption problems which may be an important source of errors in RQPA. This problem has been extensively discussed for cements (Le Saout et al. 2011) so it is not further treated here. We want just to mention that this effect may be corrected (Brindely 1945; Taylor and Matulis 1991) but its implementation in practice is extremely difficult.

On the other hand, OPC samples contain phases with different hardness's. The necessary clinker grinding may lead to higher concentrations of brittle and softer phases (gypsum, alite) in the finer fraction and harder phases (e.g., belite) in the coarser fraction. This was already demonstrated by Gutteridge in 1984 and therefore, ground samples should not be sieved.

Some OPC samples contain unstable phase(s) in room conditions. Sample preparation should be carried out to avoid/minimize sample alteration. In this case, there are differences between anhydrous OPCs and hydrated pastes. For anhydrous OPCs, the main unstable phase is free lime that is hydrated to portlandite and later carbonated to calcite within days under laboratory atmosphere (Fullmann and Walenta 2003). Therefore, if $\mathrm{CaO}$ is going to be analyzed, data should be recorded as soon as possible in flat-plate reflection (Bragg-Brentano) geometry, or sealed in an appropriate capillary when working in transmission (Debye-Scherrer) geometry. These considerations are even more important for OPC pastes as recently formed portlandite is very reactive and it is easily carbonated. Therefore, the flat-surface pastes should be covered with Mylar or Kapton thin tapes (see for instance, Jansen et al. 2011b). Finally, a lot of care in the experimental setup has to be devoted in order to avoid self-desiccation problems. A very recent study compared reflection versus transmission (both capillary and flat-sample) geometries for in-situ laboratory X-ray powder diffraction of Portland cement hydration at early ages (Dalconi et al. 2011). Unfortunately, the flat-sample held between two Kapton films underwent hydration stop due to self-desiccation very likely because a perfect sealing was not achieved. It was also observed that higher amounts of ettringite and portlandite were quantified analyzing Bragg-Brentano data with respect to capillary data. These discrepancies were related to sample segregation effects in reflection geometry, which is always a concern in this type of configuration.

\section{SELECTED EXAMPLES OF RIETVELD QUANTITATIVE PHASE ANALYSIS}

The initial work on RQPA of Portland clinker was published back on 1993 (Taylor and Aldrige 1993). Soon after, other works showed the advantages of this method which does not require standards or calibration curves (Moller 1995, 1998; Meyer et al. 1998; Taylor et al. 2000). Initially, the studies were focused on OPC clinkers and later expanded to different types of cements. The accuracy of such type of analysis was investigated (De la Torre and Aranda 
2003). Subsequently, RQPA has been employed to investigate the hydration products of several types of OPC cements. The main uses of Rietveld quantitative analysis for extracting information of OPC materials are given in Figure 1. The next subsections review some papers on these uses but the discussed list is not intended to be exhaustive.

\section{Clinkers}

A RQPA of a commercial OPC clinker was studied by high-energy ( $\lambda=0.442 \AA$ ) synchrotron powder diffraction in Debye-Scherrer (transmission) configuration (De la Torre et al. 2001b). Data for the same sample were also collected in a laboratory diffractometer $\left(\mathrm{CuK \alpha} \alpha_{1,2}\right.$, $\lambda=1.54 \AA$ ) in Bragg-Brentano (reflection) configuration. The high-resolution nature of the synchrotron data allowed establishing the phase's polymorphism without selective dissolution. This information is important not only for accurate RQPA, but also because the polymorphs may influence the strength development during hydration (Stanek and Sulovsky 2002). Furthermore, the use of capillaries of $1.0 \mathrm{~mm}$ of diameter in the synchrotron study allowed a large amount of sample to be tested which yield very reproducible diffraction intensities and so accurate RQPA results. However, the expensive nature of synchrotron measurement only allows its use for very special problems or for proof-of-principle experiments.

The use of RQPA for analyzing OPC clinkers was nicely exemplified in the study of a commercial white Portland clinker (De la Torre et al. 2003). The RQPA results of the white clinker normalized to $100 \mathrm{wt} \%$ of crystalline phases gave $77.3 \mathrm{wt} \%$ of $\mathrm{C}_{3} \mathrm{~S}, 19.8 \mathrm{wt} \%$ of $\mathrm{C}_{2} \mathrm{~S}$ and $2.9 \mathrm{wt} \%$ of $\mathrm{C}_{3} \mathrm{~A}$. However, Bogue calculations from XRF data gave: 71.3, 12.2 and

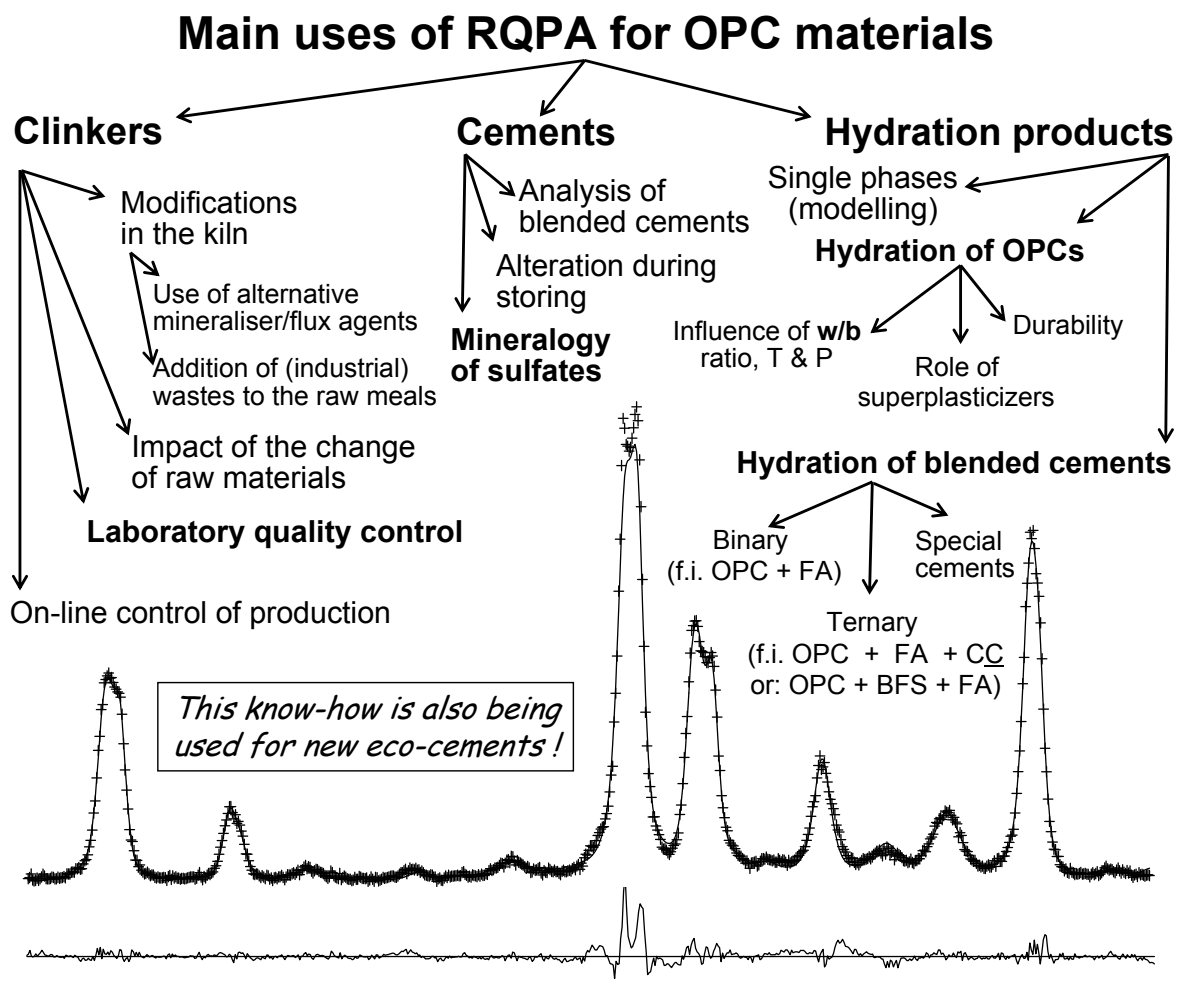

Figure 1. Main uses of Rietveld quantitative phase analysis for studying ordinary Portland clinkers, cements and hydration products. 
$13.1 \mathrm{wt} \%$, respectively. It is clear that there is a strong disagreement between RQPA and Bogue calculations for $\mathrm{C}_{3} \mathrm{~A}$ which is necessary for understanding cement sulfate-resistance properties. Annealing the commercial white clinker at $1500{ }^{\circ} \mathrm{C}$ for 1 hour allowed obtaining a sample with obviously the same elemental analysis, but quite different crystalline phase content: $76.8 \mathrm{wt} \%$ of $\mathrm{C}_{3} \mathrm{~S}, 14.1 \mathrm{wt} \%$ of $\mathrm{C}_{2} \mathrm{~S}$ and $9.1 \mathrm{wt} \%$ of $\mathrm{C}_{3} \mathrm{~A}$, see Figure 2, demonstrating the advantage of RQPA over XRF.

The use of synchrotron X-ray powder diffraction (SXRPD) for grey clinker analysis gave better results since the data have higher resolution (peak widths are narrower) and the intensities are much more accurate (working in transmission with a short wavelength allows to test a much larger amount of crystallites). An initial study with commercial grey OPC clinkers showed alite phase coexistence for a range of magnesium contents (De la Torre et al. 2005), see Figure 3. The $\mathrm{MgO}$ and $\mathrm{SO}_{3}$ contents, for a clinker showing alite coexistence, were 1.24 and $1.15 \mathrm{wt} \%$, respectively (measured by XRF). Furthermore, the ACn content was determined in several samples using the internal standard approach and it was shown that white OPC clinkers have much higher contents than grey OPC clinkers, $\sim 20$ and $\sim 8 \mathrm{wt} \%$, respectively. The study of NIST reference material RM 8488 by the internal standard method gave an overall

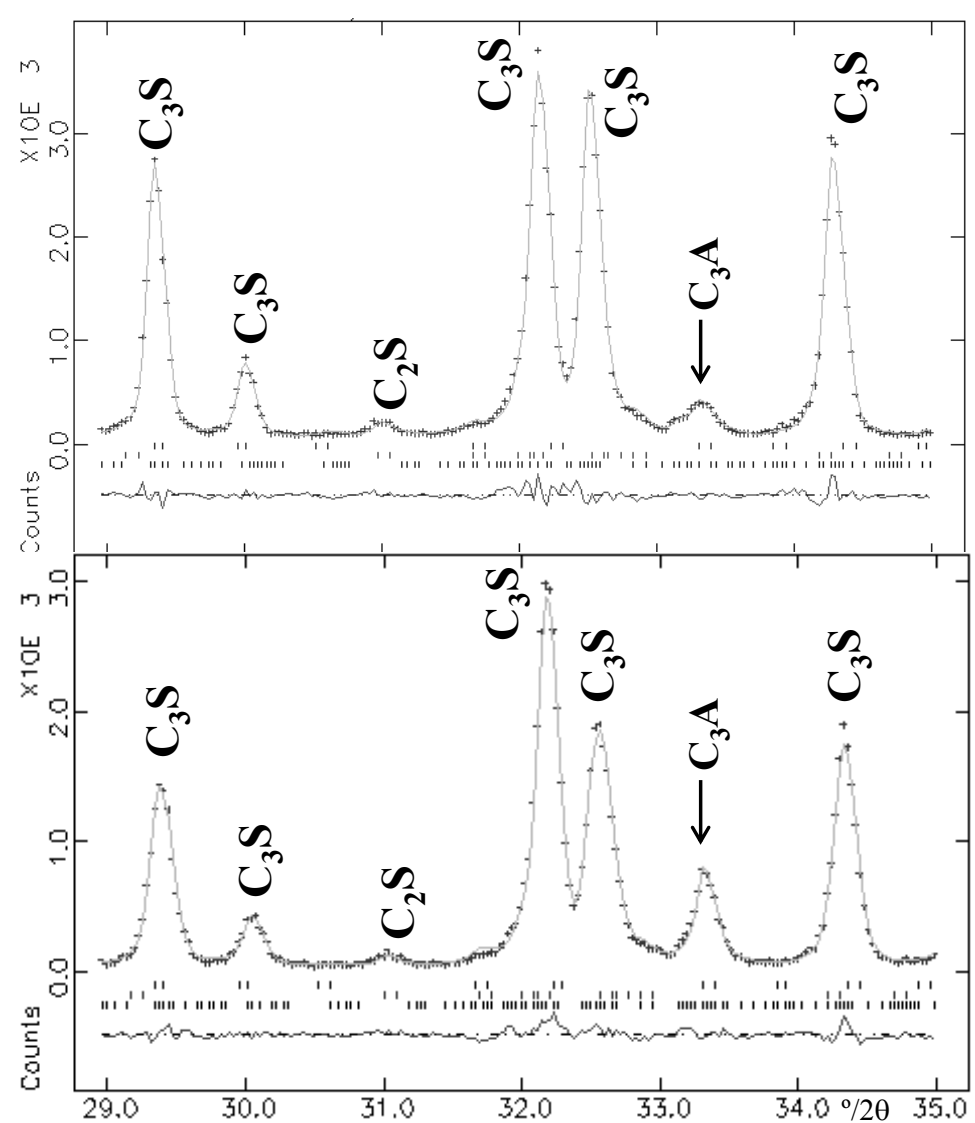

Figure 2. (top) Selected region of a Rietveld plot $\left(\mathrm{CuK} \alpha_{1,2}\right)$ for a commercial white Portland clinker with main peaks labeled. (bottom) Selected region of the Rietveld plot for the same clinker annealed at 1500 ${ }^{\circ} \mathrm{C}$ for 1 hour. Note the increase of the $\mathrm{C}_{3} \mathrm{~A}$ main diffraction peak (modified after De la Torre et al. 2003). 


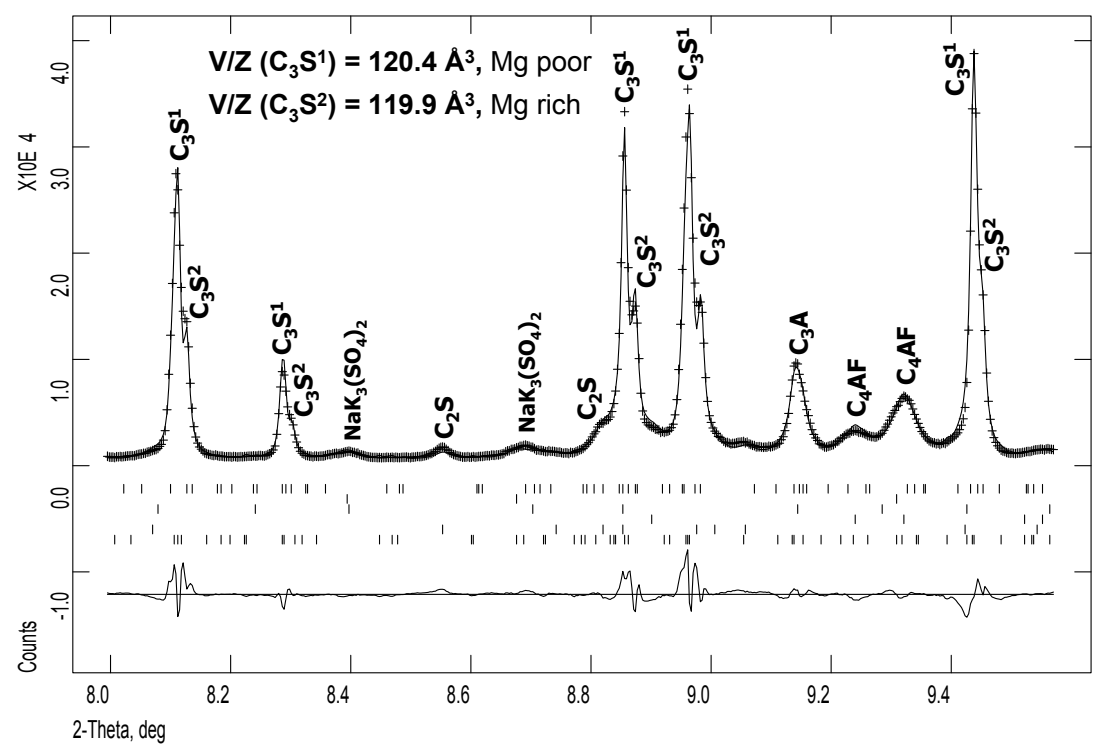

Figure 3. Selected region of a high-resolution synchrotron Rietveld plot $(\lambda=0.43 \AA)$ for a commercial grey Portland clinker with main peaks labeled. Note the alite phase coexistence (modified after De la Torre et al. 2005).

ACn content of $8 \mathrm{wt} \%$ (De la Torre et al. 2006). It was also possible to use synchrotron X-ray powder diffraction to characterize the quality of laboratory powder diffraction data. One study analyzed the same OPC by SXRPD data, LXRPD-CuK $\alpha_{1}$ and LXRPD-CuK $\alpha_{1,2}$ (see Fig. 4). It was concluded that LXRPD-CuK $\alpha_{1}$ diffraction peaks were only slightly broader than those in the SXRPD pattern (De la Torre et al. 2006).

The quantification of the ACn content in Portland clinkers has been a matter of deep research for a number of years. Suherman et al. (2002) already carried out a thorough study using SXRPD and LXRPD as well as internal and external standard approaches. Furthermore, selective dissolution and point-counting microscopy were also used to have the best possible results. The overall ACn contents for NIST reference clinker materials RM8486, RM8487 and RM8488 were $\sim 6 \mathrm{wt} \%, \sim 11 \mathrm{wt} \%$ and $\sim 7 \mathrm{wt} \%$, respectively. Two commercial OPC grey clinkers were also analyzed and the determined ACn contents were 14 and $8 \mathrm{wt} \%$. These NIST reference materials were also studied by RQPA and the importance of correct peak shape fits was stressed in order to have good RQPA results (Pritula et al. 2003). A subsequent analysis was dedicated to the study of the overall non-diffracting content in several commercial grey OPC clinkers and cements. The used approach was the internal standard (spiking) method and ACn contents close to $20 \mathrm{wt} \%$ were determined (Whitfield and Mitchell 2003).

Neutron powder diffraction (NPD) has also been used for RQPA of clinkers. NPD refinements were found to be more stable than the X-ray ones, but there was not any notable difference in the final determined phase assemblage (Pritula et al. 2004a). Furthermore, NPD, SXRPD and LXRPD were used to study the NIST reference clinker material RM8488. The study gave quite satisfactory results although it seems that the quantification of $\mathrm{C}_{3} \mathrm{~A}$ by NPD was somewhat unstable (Peterson et al. 2002, 2006).

$\mathrm{CO}_{2}$ emission reduction can be obtained in Portland clinkers manufacturing by partly replacing calcite by calcium oxide-bearing waste materials such as blast furnace slag or fly ash. RQPA was used to derive the phase assemblages of these laboratory-prepared clinkers 


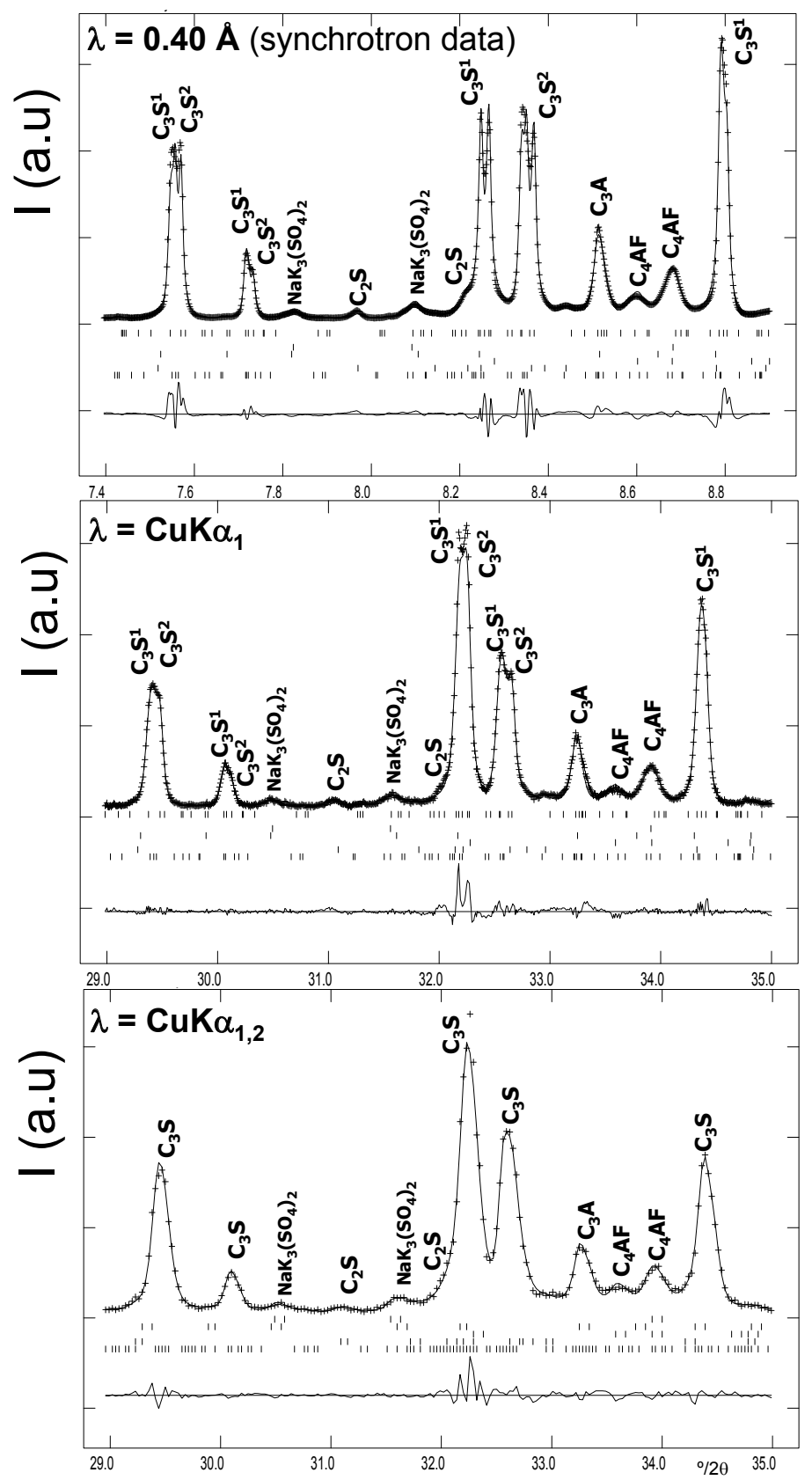

Figure 4. Selected region of the Rietveld plots for the same commercial Portland clinker. Data were collected at: ID31 diffractometer of ESRF synchrotron (top), a laboratory diffractometer with a Ge(111) primary monochromator (middle), and a laboratory diffractometer with a graphite secondary monochromator (bottom). Note the similar resolution of synchrotron and $\mathrm{CuK \alpha} \alpha_{1}$ patterns (modified after De la Torre et al. 2006). 
using these special raw meals (Chen and Juenger 2009a,b). However, it is now recognized that these materials (blast furnace slag or fly ash) are more eco-friendly as additions to ordinary Portland clinkers to produce blended cements in Europe or directly in the fabrication of concretes (North America). Therefore, the use of RQPA for studying these additions will treat in the next section dedicated to OPC cements.

Another general use of RQPA is to study the role of mineralizing/flux agents in the kiln or the processing of industrial wastes in the kilns by analyzing the resulting clinker phase assemblage. As it has been described (Herfort et al. 2010), the mechanism of action of the trace elements incorporated into the clinker can be divided in two main steps depending on the amount of these elements: i) at low concentration, trace elements enter into the structure of the initial phases of the clinker as solid solutions $\left(\mathrm{C}_{3} \mathrm{Sss}, \mathrm{C}_{2} \mathrm{Sss}, \mathrm{C}_{3} \mathrm{Ass}, \mathrm{C}_{4} \mathrm{AFss}\right)$; ii) at higher concentrations, the presence of new phases may be detected and quantified (Gineys et al. 2011). RQPA may help in both cases, initially by following the unit cell variations of the solid solution(s) and secondly, by quantification of the new phases. The implications of processing industrial waste(s) in the Portland kilns have been studied by RQPA. For instance, this approach has been used to evaluate the effects of chromium and nickel additions to Portland clinker raw meals. The final goal was to better characterize the processing of galvanic sludge which is the main hazardous solid waste produced by some metallurgical industries. A small decrease in the $\mathrm{C}_{3} \mathrm{~S}$ contents were measured as the amount of $\mathrm{Ni}$ and $\mathrm{Cr}$ in the raw meals increases (Ferreira et al. 2008).

For the production of Portland clinkers, mineralizers and/or fluxes are added to the raw mixes to accelerate reactions and enhance burnability. The traditional fluxes $\left(\mathrm{Fe}_{2} \mathrm{O}_{3}\right.$ and $\mathrm{Al}_{2} \mathrm{O}_{3}$ ) may be partially substituted by the mineralizing pair $\mathrm{CaF}_{2} / \mathrm{CaSO}_{4}$ to produce clinkers with low aluminate contents at temperatures close $1400{ }^{\circ} \mathrm{C}$. This is particularly useful for manufacturing white Portland clinkers because of the potential for energy conservation and seawater resistance. However, new phases may appear and in order to carry out RQPA, the crystal structures must be known. A work (Pajares et al. 2002) identified fluorellestadite in the mineralized white Portland clinker. Its crystal structure was determined and a satisfactory RQPA of the mineralized white Portland clinker was obtained. Figure 5 displays the Rietveld plot of this mineralized white Portland clinker, and a similar Rietveld plot for an ordinary white Portland clinker is also given for the sake of comparison.

\section{Cements}

RQPA in OPC cements can be used for a number of applications including: i) quantification of the crystalline phases in OPCs, including the ACn content if needed; ii) to analyze the amount and role of sulfate-containing phases; iii) to study the mineralogical phase assemblage in the materials used as addition(s), including their ACn contents; iv) to quantify all phases in blended OPC cements. The overall amorphous content has been studied in OPC clinkers as previously discussed. This type of study has also been carried out in cements and a thorough study by the external standard method (Jansen et al. 2011a) concluded that no significant amorphous content could be proven in that particular analyzed OPC cement.

Commercial OPCs contain sulfate carriers in variable amounts. Gypsum (or other calcium sulfates) is added to the clinker during the milling process, where it may partially dehydrates to bassanite or even to soluble anhydrite-III. Due to different hydration kinetics of these phases, it is necessary to characterize the mineralogical composition of sulfate in a cement system in order to reach an optimal and reproducible setting and cement hydration (Seufert et al. 2009a). The formations and transformations of the five different phases in the $\mathrm{CaSO}_{4}-\mathrm{H}_{2} \mathrm{O}$ system have been studied in detail (Christensen et al. 2008). The use of RQPA for determining the amounts of gypsum, bassanite and anhydrite in OPC was already demonstrated several years ago (Fullmann and Walenta 2003; Walenta and Fullmann 2004; Seufert et al. 2009b). The 


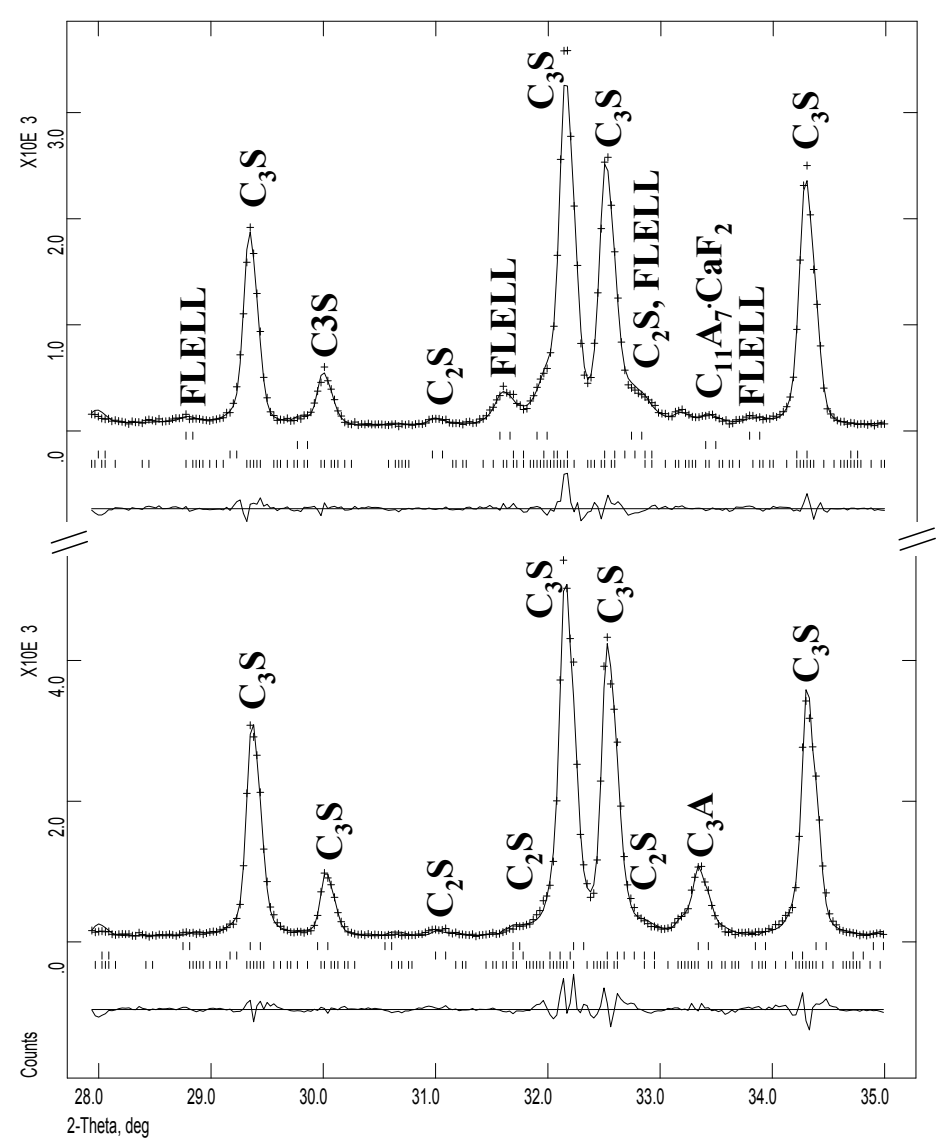

Figure 5. (top) Selected region of a Rietveld plot $\left(\mathrm{CuK} \alpha_{1,2}\right)$ for a mineralized white Portland clinker. (bottom) Selected region of the Rietveld plot for an ordinary commercial white Portland clinker. The main peaks are labeled and FLELL stands for fluorellestadite (modified after Pajares et al. 2002).

mineralogy of the sulfate source is very important for the fluidity, setting and hydration of mortars and concretes (Tang and Gartner 1988; Rossler et al. 2008). This technique has been very recently used for quantitative determination of the hydration products formed within minutes of mixing (e.g., ettringite, syngenite and secondary gypsum), to help identify the cause(s) of early stiffening (Ramlochan and Hooton 2011).

Today supplementary cementitious materials (SCMs) are widely used in concrete either in blended cements or added separately in the concrete mixer. The use of silica rich materials influences the amount and kind of hydrates formed and thus the volume, the porosity and finally the durability of these materials (Lothenbach et al. 2011). Therefore, it is easy to understand that the mineralogical phase assemblage in different common additions has been deeply studied including PFA, bottom ash, metakaolin and BFS (Kumar et al. 2008; Korpa et al. 2009; Gonçalves et al. 2009; De Weerdt et al. 2011; Narmluk and Nawa 2011). Furthermore, RQPA has also been used to characterize other less common additions such as drinking water treatment plant sludge (Husillos-Rodriguez et al. 2010) or natural zeolites (Snellings et al. 2010). Table 4 reports a RQPA study of a fly ash carried out in our laboratory by the internal standard method described above. Figure 6 (top) shows the Rietveld plot for 
Table 4. Rietveld quantitative phase analysis (wt\%) of a fly ash.

\begin{tabular}{lcc}
\hline Phase & $\begin{array}{c}\text { Fly ash }+ \\
\text { internal standard } \\
\text { RQPA direct result }\end{array}$ & $\begin{array}{c}\text { Fly ash analysis } \\
\text { Final result }\end{array}$ \\
\hline Mullite & $9.5(2)$ & $11.1(4)$ \\
Hematite & $3.9(2)$ & $4.6(6)$ \\
Quartz & $7.4(2)$ & $8.7(6)$ \\
Wollastonite & $0.8(2)$ & $1.0(6)$ \\
Corundum $\left(W_{S}=47.7 w t \%\right)$ & $\left(R_{S}=\right) 78.3(6)$ & --- \\
ACn content & ---- & $\mathbf{7 4 . 6}$ \\
\hline " ACn stands for amorphous plus not-quantified crystalline phase(s) which includes misfitting problems \\
and not-computed phase(s).
\end{tabular}

this type of analysis with the main peaks labeled. An overall ACn content of $\sim 75 \mathrm{wt} \%$ was obtained with mullite and quartz being the main crystalline phases (see Table 4).

Finally, the analysis of blended cements containing BFS and PFA additions by RQPA (with internal standard) was already reported several years ago (Westphal et al. 2002; Walenta Fullmann and 2004). Many more studies have been reported in this subject mainly linked to the hydration characterization. Hence, some of these papers will be discussed in the next subsection. As an example of this type of analysis, Figure 6 (bottom) shows the Rietveld plot of a RQPA for a blended OPC cement obtained with the fly ash described in the previous paragraph. It was possible even to quantify the mullite content, in the cement. This number may be used to track down the approximate amount of fly ash added to the cement in the industry. Quartz is not a suitable compound to carry out this type of calculations as it may be present in the gypsum and/or in the additions like limestone, chert, etc.

\section{Hydration products}

RQPA has been employed for a number of applications related to the hydration reactions of OPC materials. The uses have been expanded from the hydration of model systems (for instance a single phase or an artificial mixture, Bellman et al. 2010) to blended cements and the role of admixtures and superplasticizers. It must be highlighted that the impact of admixtures on the hydration kinetics of Portland cement has been recently reviewed (Cheung et al. 2011) although that paper focused on the materials and not on the techniques to be used.

RQPA was used to study the hydration reactions of commercial OPC in reflection geometry with laboratory data (Scrivener et al. 2004). The results were satisfactorily compared to those obtained from thermal analysis and electron microscopy. RQPA, using the internal standard approach in transmission geometry, was employed for studying OPC hydration products (Mitchell et al. 2006). The data obtained from capillary measurements showed little preferential orientation, and produced the progression of phase contents expected from the reaction. This study highlighted the benefits of the transmission geometry as more particles are measured which yields more reliable quantitative results. The early hydration of white Portland cement was also studied by in situ X-ray powder diffraction (reflection geometry) at defined temperatures and with different water/cement ratios (Hesse et al. 2008, 2009). The hydration of an OPC cement at 28 days was studied by RQPA using the external and internal standard methods including the role of isopropanol to stop the hydration reaction (Le Saout et al. 2007). Figure 7 displays the typical Rietveld plot for that material where the relevant peaks are labeled.

RQPA based on in-situ synchrotron powder diffraction was used to monitor the evolution of hydrous phases during early hydration with a time resolution of 10 seconds (Weyer et al. 2005). A related work but with lower time resolution (minutes) studied the hydration process 

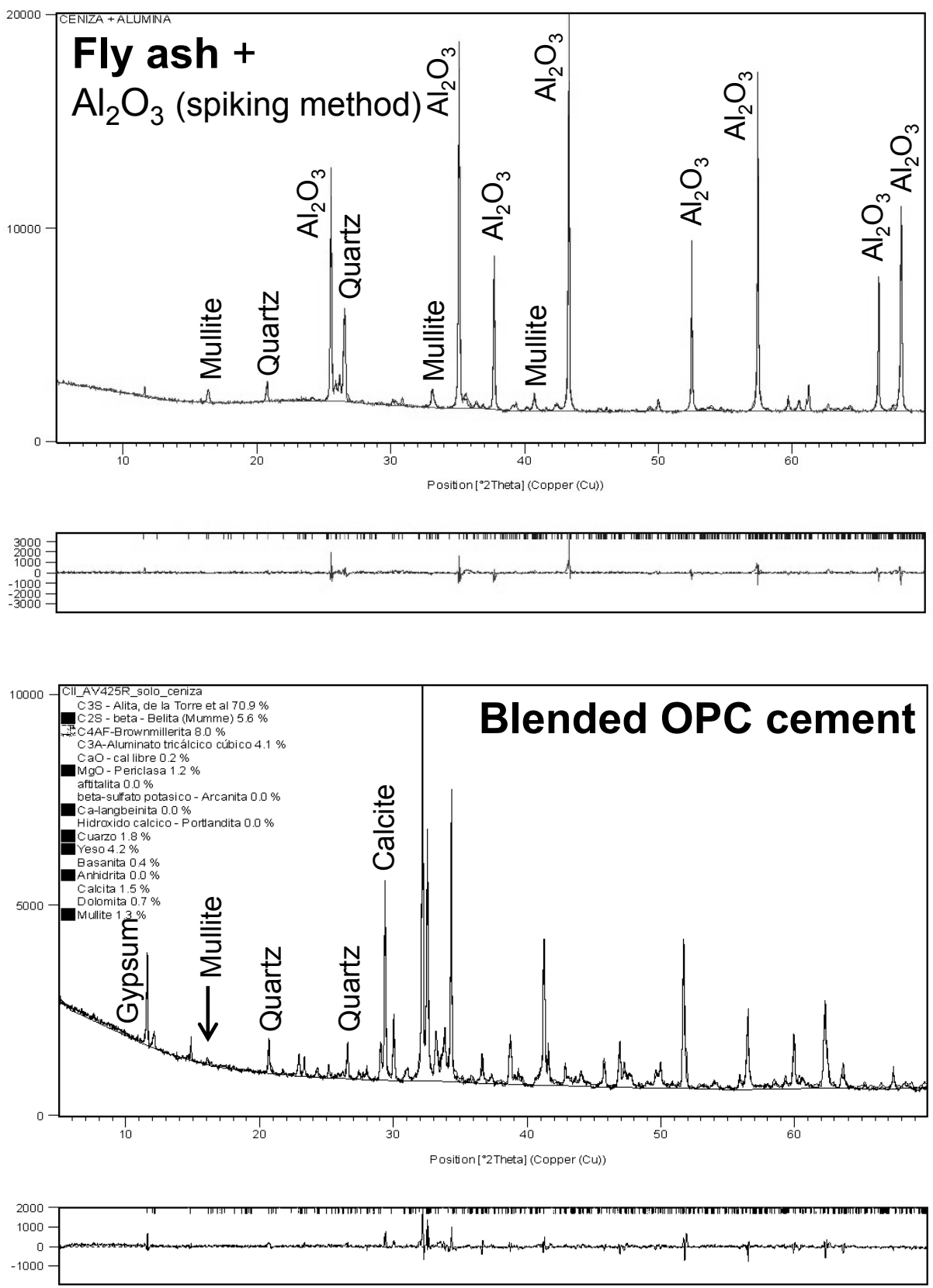

Figure 6. (top) Full region of a Rietveld plot $\left(\mathrm{CuK \alpha} \alpha_{1}\right)$ for a fly ash mixed with $\mathrm{Al}_{2} \mathrm{O}_{3}$ as internal standard $(47.7 \mathrm{wt} \%)$. The main peaks are labeled. (bottom) Full region of the Rietveld plot $\left(\mathrm{CuK \alpha} \alpha_{1}\right)$ for an industrial blended OPC obtained from that fly ash. The main diffraction peaks, which are not due to clinker phases, are highlighted. 


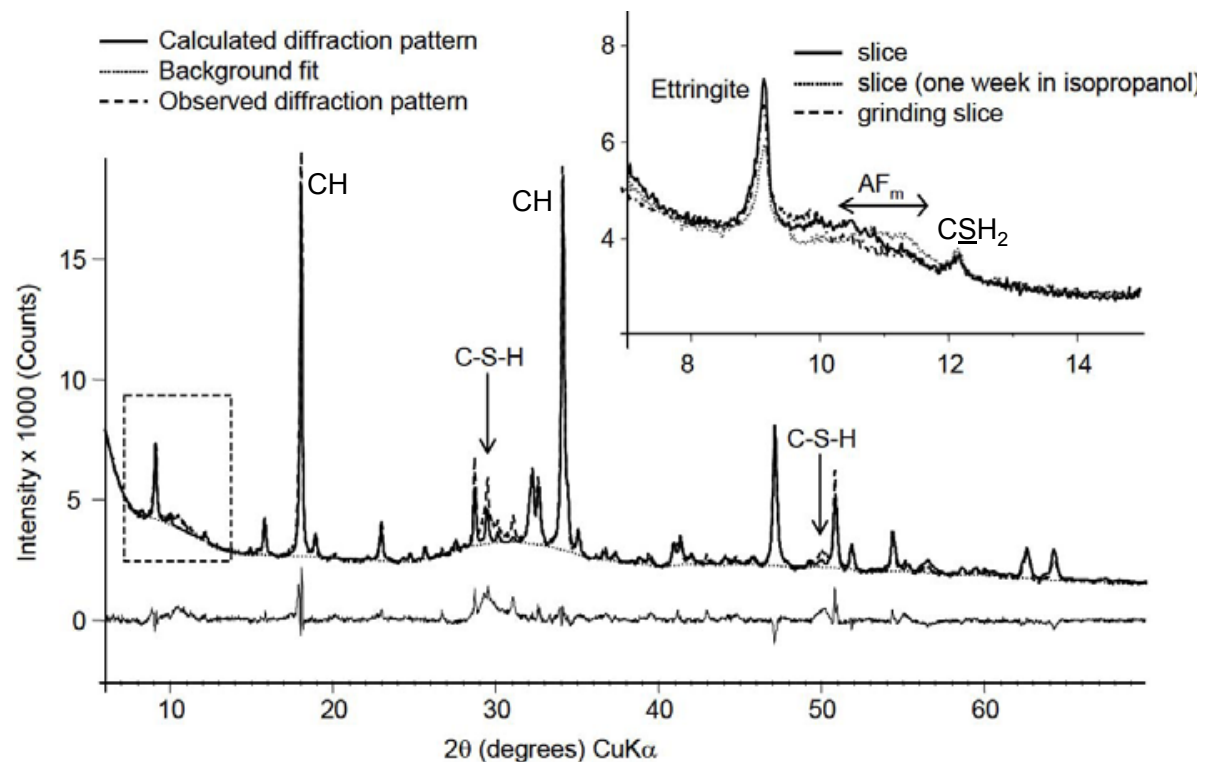

Figure 7. Rietveld plot $\left(\mathrm{CuK} \alpha_{1,2}\right)$ for a 28 days hydrated OPC cement. The upper right inset shows the influence of isopropanol for the cement hydrated at 28 days (modified after Le Saout et al. 2007).

on synthetic clinker phases $\left(\mathrm{C}_{3} \mathrm{~A}\right.$ and $\left.\mathrm{C}_{4} \mathrm{AF}\right)$ and on commercial OPC cements (Merlini et al. 2007a,b). Furthermore, synchrotron powder diffraction was also used to monitor the evolution of ettringite in $\mathrm{C}_{3} \mathrm{~A}$-gypsum synthetic mixture and in commercial OPC cement systems during the first hours of the hydration process (Merlini et al. 2008). In-situ synchrotron RQPA was also carried out for studying the very early hydration of Class $\mathrm{A}$ and $\mathrm{H}$ oil well Portland cements with different amounts of $\mathrm{CaCl}_{2}$ at 25 and $50{ }^{\circ} \mathrm{C}$ (Jupe et al. 2007). On the other hand, synchrotron radiation may be used in more sophisticated types of characterization. For instance, high-energy synchrotron X-ray microdiffraction was used to quantify the orientation distribution of ettringite crystals. Diffraction images were analyzed using the Rietveld method to obtain information on textures within thin slabs of mortars (Wenk et al. 2009).

The hydration reactions of an alkali-poor and an alkali-rich OPC were followed by RQPA. Significant differences during the early hydration were measured due to the presence of syngenite, $\mathrm{K}_{2} \mathrm{Ca}\left(\mathrm{SO}_{4}\right)_{2} \cdot \mathrm{H}_{2} \mathrm{O}$, when the alkali content is high and secondary gypsum when the alkali content is low. Furthermore, the pore solutions of the hydrated cements were analyzed and super- or undersaturations for relevant minerals were calculated (Stark et al. 2008). In situ $\mathrm{X}$-ray diffraction for monitoring cement hydration was used to study well defined Portland cement clinkers consisting of alite and aluminate doped with different amounts of $\mathrm{Na}_{2} \mathrm{O}$. Other techniques such as isothermal conduction calorimetry and differential scanning calorimetry, scanning electron microscopy and ${ }^{27} \mathrm{Al}$ NMR technique were also used (Wistuba et al. 2007). Finally, flash setting accelerators (both alkali-rich and alkali-free) are a class of admixtures commonly used for sprayed concrete during tunnel excavation. RQPA was also used to studying the setting behavior in this special application (Maltese et al. 2007).

RQPA has been used in many works to study the hydration reactions of blended cements. Initially, this technique was used to analyze the hydration progress of cement pastes prepared by adding BFS and limestone powder (Hoshino et al. 2006). Selective dissolution was also employed to distinguish between the amorphous contents coming from BFS and newly-formed 
CSH gel (the amorphous Calcium-Silicate-Hydrated gel formed in the hydration of the calcium silicates). It was concluded that BFS accelerates the hydration of $C_{3} S, C_{3} A$ and especially $C_{4} A F$. The early age hydration and pozzolanic reaction in natural zeolite blended Portland cements has been studied by in situ synchrotron RQPA to determine the reaction kinetics and products (Snellings et al. 2010). A deep study was also carried out to quantitatively explain the effect of water curing condition on compressive strengths of fly ash cement pastes (Termkhajornkit et al. 2006). Replacement ratios of fly ash were $0 \%, 25 \%$ and $50 \%$ of total powders and the water to binder ratio was relatively low, 0.80 and 1.00 by volume. The time evolution of every OPC initial phase was worked out by RQPA. Unfortunately, the time evolution of portlandite was not quantitatively reported in that paper. The hydration degree of belite was the most affected parameter by the fly ash. On the other hand, a very recent and complete study used RQPA, together with thermogravimetry, scanning electron microscopy and isothermal calorimetry, in order to understand the hydration mechanisms of blended Portland cements containing fly ash and limestone powder (De Weerdt et al. 2011). In addition, pore solution analysis and thermodynamic modeling techniques were also employed. The time-evolution of all phases during hydration were studied (including portlandite from TGA and RQPA), and not only the pozzolanic effect was studied, but the variations in chemical shrinkages were also understood. Furthermore, the effect of fly ash on the kinetics of Portland cement hydration at different curing temperatures has also been investigated by RQPA (Narmluk and Nawa 2011). The hydration reactions of OPC were quantified by RQPA and the overall degree of fly ash hydration was determined from a selective dissolution method.

Ternary binders composed of OPC, calcium sulfoaluminate clinker (CSA) and anhydrite were examined in order to study the impact of variations of the OPC:CSA:CS ratio on the hydration process and related mortar properties. RQPA was used to determine the mineralogical composition of the starting cementitious materials. Thermodynamic modeling was used to establish the phase assemblage which was also studied by calorimetry, DTA-TGA, SEM and X-ray powder diffraction for phase identification (Pelletier et al. 2010). RQPA and thermal methods were used to determine the phase development up to 28 days of hydration in normal and ultra-high performance cementitious systems (UHPC) that contains silica fume and fly ash (Korpa et al. 2009). For the calculation of the ACn content, the vacuum dried powdered specimens were mixed with $\mathrm{ZnO}$ as internal standard. For both formulations the most remarkable changes of the phase contents were measured in the first few days of hydration.

To finish this section we would like to highlight that many hydrated phases may be present in a given hydrated/hydrating sample. Figure 8 displays the Rietveld plot of a sample showing one of the richest phase assemblage found in our laboratory. The peaks are labeled to easily identify each crystalline phases. The crystalline phases of this hydrated cement are mainly arising from the calcium sulfoaluminate cement fraction but we choose this sample to illustrate the amount of phases that can coexist in a paste (Fig. 8, Table 3).

\section{Durability studies}

Rietveld quantitative phase analysis may also help to understand/characterize the durability of the resulting mortars and concrete. Deterioration of cementitious building materials is often caused by sulfate attack at moderate temperatures due to delayed ettringite formation. Hence, several studies addressed this issue using RQPA (Katsioti et al. 2011). For instance, four cements were used to address the effect of tricalcium silicate content on external sulfate attack in sodium sulfate solution (Shanahan and Zayed 2007). Durability was studied by using linear expansion and compressive strength. Phases associated with deterioration were examined using scanning electron microscopy and RQPA. The resistance to sulfate attack of mixtures accelerated with alkali-free and alkaline accelerators was also studied by a number of techniques including RQPA which enabled the quantification of ettringite and gypsum over time (Paglia et al. 2003). On the other hand, thaumasite is mostly observed at low temperatures 

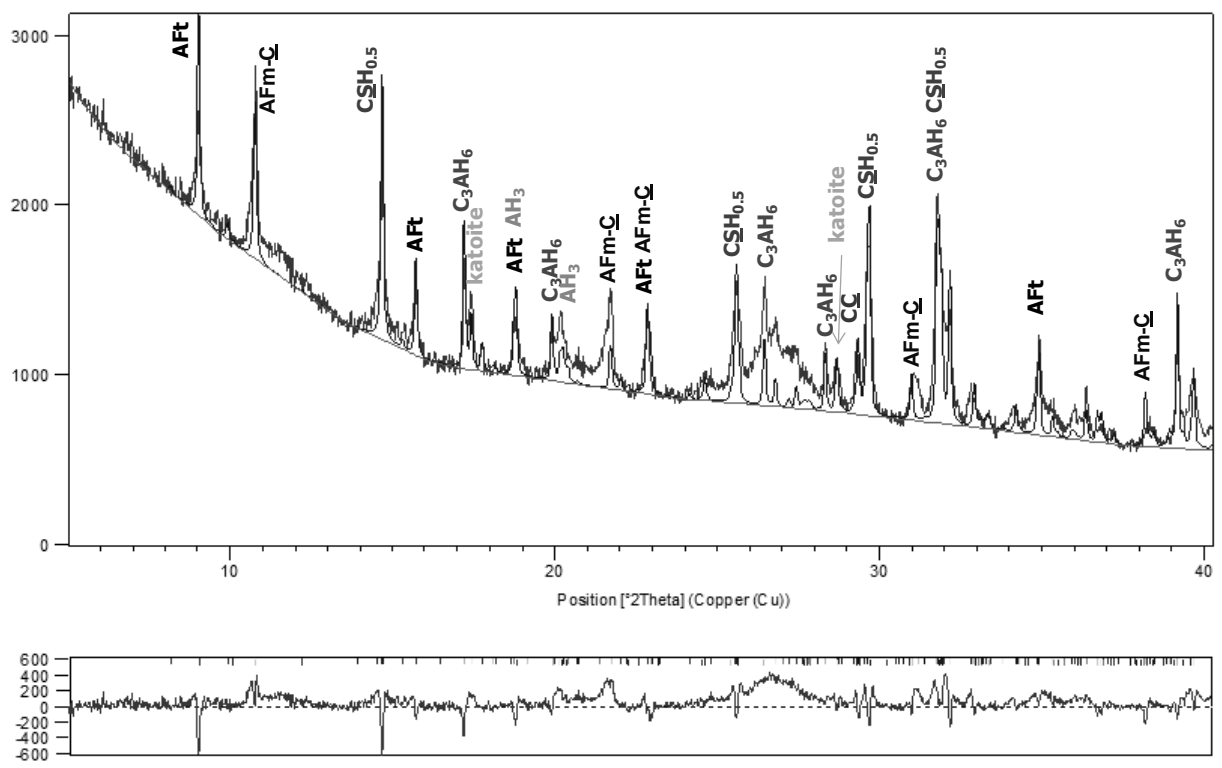

Figure 8. Rietveld plot $\left(\mathrm{CuK} \alpha_{1}\right)$ of a fully hydrated blended cement paste mainly composed of calcium sulfoaluminate cement. The main crystalline peaks are labeled.

(usually lower than $15^{\circ} \mathrm{C}$ ). Hence, the effect of ettringite on thaumasite formation was studied in synthetic OPC materials using this methodology (Kholer et al. 2006). It must be highlighted that ettringite and thaumasite form a solid solution that has been extensively studied (Barnett et al. 2002; Torres et al. 2004).

Another durability concern in OPC concretes is the alkali-aggregate/alkali-silica reaction (see for instance: Thomas et al. 2006; and references therein). Some aggregates, mainly silica but also carbonate, may provoke the expansion with failure of OPC concretes. RQPA has been employed to study the aggregates with the final aim to understand these reactions (Grattan-Bellew et al. 2010). Furthermore, this technique has also been employed, plus other characterization tools, to study the alkali-aggregate reaction in OPC and waterglass-alkaliactivated slag mortars (Puertas et al. 2009).

Finally, composition and microstructure changes of cement pastes under a heating and cooling cycle were monitored by neutron powder diffraction. The parameters involved in the study were the heating ramp, the state of the sample (in block or ground) and the type of cement. Unfortunately, the Rietveld method was not applied to quantify the phases in the mixtures (Castellote et al. 2004). Neutron powder diffraction was subsequently used for studying the phase composition changes of cement pastes during accelerated carbonation experiments (Castellote et al. 2008).

\section{Selective dissolution}

Selective dissolution may be applied to OPC clinkers (or cements) or to blended cements with different methodologies (Gutteridge 1979; Luke and Glasser 1987). For OPC clinkers, both aluminates and silicates residues can be obtained. This is very useful for ensuring the polymorph present in the samples as the enriched phase may be identified much more easily. On the other hand, selective dissolution of blended cements is also used to determine the hydration degree of the addition (for instance fly ash or blast furnace slag). In these cases, 
special selective dissolution methodologies have been developed (see for instance Ben-Haha et al. 2010).

In 2003, Lundgaard and Jons described the application of RQPA to the aluminate residues of grey Portland clinkers. Several NIST reference clinkers were analyzed. The salicylic acid/ methanol extraction method (SAM) was used to dissolve silicate phases (alite, belite) and free lime. So, the minor content phases, aluminate, ferrite and sulfates were enriched. Furthermore, residues obtained from the chemical treatment of three NIST reference materials RM8486, RM8487 and RM8488 were analyzed by SEM and RQPA. The main finding was that chemical treatment was not fully selective/quantitative (Pritula et al. 2004b). So, this methodology is appropriate for enriching the low content phases. However, selective dissolution and RQPA of the residues does not directly improve the accuracy of the analytical results.

On the other hand, special selective dissolutions for studying the hydration of blended cements have already been discussed above (Hoshino et al. 2006; Termkhajornkit et al. 2006; Brunet et al. 2010).

\section{INTERCOMPARISON AND COMPARISON WITH OTHER METHODS}

Before comparing the results of RQPA of cements with other techniques for quantitative mineralogical analyses, RQPA results of different laboratories should be compared. We highlight that this is possible for clinkers and cements but not for pastes as the evolving/ unstable nature of the samples do not allow to easily carry out an inter-laboratory study. Round robin (inter-laboratory) studies of RQPA were initially carried out for several types of samples but not OPCs (Toraya et al. 1999; Madsen et al. 2001; Scarlett et al. 2002). More recently, a partial round robin on RQPA of cement samples was published (Stutzman 2005; Stutzman and Leigh 2007). Unfortunately, the accuracy and uncertainty of the OPCs RQPA were not tested. Four cement reference specimens were prepared using NIST SRM clinkers compounded with known amounts of gypsum, bassanite, anhydrite, and/or calcite. The results of this study were used to estimate the inter- and intra-laboratory precision and bias of phase abundance determinations. Values of repeatability and reproducibility were given, but the statistical study was only based on the precision of the measurements/analyses. To evaluate the accuracy of the results, the use of these samples is not fully adequate since the "true" mineralogical compositions were not known. In a later study (Leon-Reina et al. 2009), a round-robin was conducted with two sets of samples, artificial mixtures and commercial OPCs. Artificial mixtures were prepared by mixing (weighing) synthesized single-crystalline phases in the appropriate proportions. These two samples were used to assess the accuracy and uncertainty of the procedure, as an expected mineralogical phase fraction - the "true mineralogical percentage"-is available under the assumption of negligible ACn contents. For a level of confidence of $95 \%$, the general uncertainties were in the range 4.1-6.5\% for $\mathrm{C}_{3} \mathrm{~S}$, $2.8-5.5 \%$ for $\mathrm{C}_{2} \mathrm{~S}, 0.9-2.5 \%$ for $\mathrm{C}_{3} \mathrm{~A}, 1.3-2.4 \%$ for $\mathrm{C}_{4} \mathrm{AF}, 1.0-1.6 \%$ for gypsum and $1.5-3.8 \%$ for calcite. The obtained precision values were much better.

On the other hand, comparison of RQPA results can be carried out, with due care, with other analytical techniques. For clinkers and cements, point-counting microscopy techniques (optical and electronic) also directly measure the phase contents. In addition to these techniques, XRF directly measures the elemental compositions and, under some assumptions, a potential phase content can be established. For pastes, scanning electron microscopy, coupled to EDX microanalysis, is being utilized. However, a much straight forward method is the thermal decompositions, with their associated weight losses, as the decomposition temperature range may indicate the phase and the associate weight loss may allow measuring 
its content. Furthermore, other techniques such as calorimetry and nuclear magnetic resonance spectroscopy are emerging as quantitative tools. All these techniques are briefly reviewed next.

\section{Bogue and reverse Bogue calculation}

The most widely used method for estimating the potential phase composition of OPCs from the oxide analysis was developed long time ago (Bogue 1929; Taylor 1989) and generalized by the routine use of XRF analysis. An extensive work in this topic has been very recently reported/discussed (Le Saout et al. 2011) showing the associated errors to this methodology, so it is not further discussed here. We only want to highlight an excellent work (Crumbie et al. 2006) that employed four analytical techniques: RQPA, Bogue, optical microscopy and scanning electron microscopy coupled with energy dispersive spectroscopy (SEM-EDS); for the quantitative study of eight clinkers. That paper shows that the use of standard Bogue calculation to predict the phase composition of Portland clinkers can give serious errors.

\section{Optical and scanning electron microscopies}

After the appropriate sample treatment, optical microscopy coupled with point counting techniques can produce very reliable phase quantification especially for the silicate phases, alite and belite (Campbell and Galehouse 1991; Taylor 1997; Campbell 1999; Fullmann and Walenta 2003). However, the quantification of the aluminate and the ferrite phases is often quite difficult, due to the very small crystal size of these interstitial phases. Furthermore, the different crystallographic forms of $\mathrm{C}_{3} \mathrm{~A}$ (cubic, orthorhombic) cannot be differentiated (Walenta and Fullmann 2004). There is no need to emphasize that sample preparation, data acquisition, and data analysis are more demanding than for RQPA. It must be mentioned that the International Cement Microscopy Association http://www.cemmicro.org/ which began in 1981, develops several activities including the organization of annual meetings. The published proceedings serve as a working tool and source of informative references in the areas of clinker, cement, concrete, and other building materials.

On the other hand, SEM-EDS studies are carried out to quantify the chemical (elemental) composition of selected phases within OPCs (see for instance: Gobbo et al. 2004; Crumbie et al. 2006). Both optical and electron microscopies are good complementary techniques to RQPA of clinkers and cements (Campbell and Galehouse 1991; Stutzman and Leigh 2002; Suherman et al. 2002; Stutzman 2011 and references therein). Other electron microscopy studies can be carried out. For instance, high-resolution cold field emission-scanning electron microscopy, in addition to isothermal conduction calorimetry and RQPA of the initial cements, was used to understand the end of the induction period of OPCs (Makar and Chan 2008).

Finally, it should be kept in mind that microscopy techniques directly give volume fractions but Rietveld software usually gives weight fractions. The comparison is straightforward for anhydrous cements by using the crystallographic densities (already within the software calculations) to renormalize one of the results. However, this comparison is not straightforward for hydrating samples as the densities of some (amorphous) hydrates are not well known. The volume variation during hydration is necessary for understanding chemical shrinkages of pastes, mortars and concretes.

\section{Thermodynamic modeling}

In this approach, the calculated hydration rates of the individual clinker phases are used as the (time-dependent) input under the relevant conditions once the appropriate database is developed (Matschei et al. 2007b). The modeled data can be compared with the measured composition of pore solutions as well as with any experimental quantitative phase analysis technique (Lothenbach and Winnefeld 2006). This approach was extended to variabletemperature hydration studies (Lothenbach et al. 2008a) and it has been very recently reviewed (Damidot et al. 2011). 
For instance, this methodology (in combination with RQPA and DTA-TGA, see below) was used for characterizing the role of limestone on the hydration of Portland cement (Lothenbach et al. 2008b). Another example is its use (in combination with X-ray powder diffraction) to establish the impact of chloride on the mineralogy of hydrated Portland cement systems (Balonis et al. 2010).

\section{Thermal measurements}

Differential thermal analysis - thermogravimetric analysis (DTA-TGA) measurements may be used to quantify phases in cements and pastes. To the best of our knowledge, there are no many examples of using DTA-TGA studies for corroborating the RQPA results in clinkers and cements. However, the use of DTA-TGA is straightforward as it allows determination of the overall calcite content from its decomposition temperature, between 700 and $800{ }^{\circ} \mathrm{C}$, in OPCs. Furthermore, if portlandite has been formed by hydration of free lime, its overall content can also be determined from the DTA-TGA study, as its decomposition temperature is close to $450{ }^{\circ} \mathrm{C}$. Finally, DTA-TGA also allows distinguishing between gypsum and bassanite under the appropriate experimental conditions (Blaine 1995), and this was used to verify the gypsum/bassanite ratio obtained from RQPA (Leon-Reina et al. 2009).

DTA-TGA technique is widely used for studying cement pastes as it allows having an insight about the overall degree of reaction by measuring the overall water content (after subtraction of the free water). Furthermore, the evaluation of some phases may be carried out independently from their thermal decomposition temperatures. A key use is to determine the time-evolution of portlandite from RQPA and DTA-TGA measurements (Scrivener et al. 2004; Puertas et al. 2010). Furthermore, DTA-TGA and RQPA have been carried out to monitor the long-term hydration behavior of cement monoliths containing organic waste (Leoni et al. 2007), and to investigate long-term leaching in concretes (Marinoni et al. 2008).

\section{Calorimetric data}

A new approach is being developed which consists in correlating the heat flow curves with the results of RQPA. This methodology allows understanding the chemical origin of different regions/features in the calorimetric curves (hydration reactions) and also supports the accuracy of RQPA (Hesse et al. 2011). This type of study was initially carried out for synthetic cement and later used to characterize the hydration of alite including the $\mathrm{ACn}$ content which was determined by the external standard, G-method, approach (Jansen et al. 2011b). Finally, the power of this methodology (including the G-method for measuring the ACn content) has been demonstrated by characterizing the early-age hydration reactions of an OPC cement by RQPA and isothermal calorimetry (Jansen et al. 2012a). Furthermore, the same group used this methodology to understand the changes in reaction kinetics of an OPC caused by a superplasticizer (Jansen et al. 2012b).

\section{Nuclear Magnetic Resonance (NMR) spectroscopy}

NMR techniques have been increasingly employed in studies of cementitious materials mainly for understanding hydration reactions (Skibsted et al. 2002) including blended OPC cements (Dyson et al. 2007). Its full application to anhydrous OPCs samples has only been recently introduced (Poulsen et al. 2009). These authors used NMR techniques to determine the alite-to-belite Si-ratio which was compared to the alite-belite ratio determined by RQPA. Good agreement was found, although belite may be slightly underestimated under some circumstances.

The (independent) use of RQPA and NMR methods for characterizing anhydrous OPCs and the hydration reaction products has been reviewed (Skibsted and Hall 2008; Stark 2011). It should be noted that the combined use of these two techniques for quantitative analysis is not frequently used. We can highlight that ${ }^{29} \mathrm{Si}$ and ${ }^{27} \mathrm{Al}$ solid-state NMR spectroscopy with 
complementary X-ray diffraction analysis and selective dissolution techniques have been used to study the hydration of a CEM V blended cement containing pulverized fly ash and blast furnace slag in order to understand hydration processes which influence the paste microstructure (Brunet et al. 2010).

\section{GUIDELINES FOR RIETVELD QUANTITATIVE PHASE ANALYSES}

There are reported guidelines for Rietveld studies that should be known (McCusker et al. 1999). This section gives a methodology to carry out a RQPA. However, it is not a universal guideline, not being the optimum way for all cases. As the analyses are becoming more and more complex (for instance hydration reactions of blended cements), extreme care has to be exercised to carry out the best possible analysis. So, it is advisable to learn the methodology in a well-trained laboratory with previous experience in the system or at least in related-systems. Some general rules are given in the next subsections that should be cautiously taken when applied to the specific problem.

\section{Crystal structures}

Tables 1-3 give a selected compilation of crystal structures that can be used in the Rietveld control file. Many crystal structures have been already used in our laboratory but not all of them. Furthermore, sometimes there is more than one structural description available in the literature for a given phase. The methodology that we use in our laboratory to select a phase is to carry out two (or more) RQPA with the two (or more) reported structural descriptions. We select the structure that gives the best fit. This is easier to say than to fulfill. As a general rule, our approach is to select the phase which gives a lower $\mathrm{R}_{\mathrm{F}}$ factor (see McCusker et al. 1999; Toby 2006) hopefully linked to a higher quantification value. Additionally, cross-checking with other method(s) to determine the chemical compositions of the modifications is appropriate, but it is time-demanding and expensive. If needed, transmission electron microscopy coupled with chemical analysis may be used to measure average elemental substitutions in some phases.

Tables 1-3 are quite exhaustive but more phases may be present in a given powder pattern. It is not possible to deal here with every phase that may be present in a Portland cement. For instance, the authors found $\mathrm{ZnO}$ in a clinker produced with used tyres which were employed as alternative fuel. Therefore, the methodology to finish the RQPA of an OPC material is to identify the phase(s) responsible for any additional diffraction peak in the powder pattern, if needed. This is usually carried out by comparing the extra diffraction peaks with those reported in the Powder Diffraction Database (www.icdd.com). However, a good chemical knowledge of the system is very important as the powder patterns may be very complex and the identification may not be conclusive. The second step is to find the structural description for that phase in order to be inserted in the Rietveld control file. One can check in the bibliography and on the internet. The fastest way is to search that phase in three structural data bases: i) AMCSD "American Mineralogist Crystal Structure Database" (http://rruff.geo.arizona.edu/AMS/amcsd. php); ii) COD "Crystallography Open Database" (http://www.crystallography.net); and iii) ICSD "Inorganic Crystal Structure Database" (http://www.fiz-karlsruhe.de/icsd.html). If more than one phase may explain a set of extra peaks, then the approach described in the previous paragraph applies.

Finally, the crystal structure to be used in the quantification has sometimes to be adapted to describe a given stoichiometry. This is illustrated with the Katoite structure which is a solid solution, $\mathrm{Ca}_{3} \mathrm{Al}_{2}(\mathrm{OH})_{12-4 x}\left(\mathrm{SiO}_{4}\right)_{x}(0 \leq x \leq 1.5)$, that may go from the end member hydrogarnet, $\mathrm{Ca}_{3} \mathrm{Al}_{2}(\mathrm{OH})_{12}(x=0)$, up to $\mathrm{Ca}_{3} \mathrm{Al}_{2}(\mathrm{OH})_{6}\left(\mathrm{SiO}_{4}\right)_{1.5}$. Another examples is brownmillerite, $\mathrm{Ca}_{4}\left(\mathrm{Fe}_{4-x} \mathrm{Al}_{x}\right) \mathrm{O}_{10}$, where the iron/aluminum ratio is variable (Redhammer et al. 2004) but close to $\mathrm{x}=2$ in Portland cements. In addition to the variable iron content, for a fixed $\mathrm{Fe} /$ 
$\mathrm{Al}$ ratio, the occupations of $\mathrm{Al}$ and $\mathrm{Fe}$ on tetrahedral and octahedral sites influence the peak intensities (Neubauer et al. 1996; Neubauer and Mayerhofer 2000). It is known that very fast cooling leads to lower intensity of the (020) peak of $\mathrm{C}_{4} \mathrm{AF}$ (located at $12.2^{\circ} 2 \theta \mathrm{CuK} \alpha$ ) due to a random distribution of $\mathrm{Al}$ and $\mathrm{Fe}$ over the two sites, when compared to the main reflection (141) located at $33.7^{\circ} 2 \theta \mathrm{CuK} \alpha$. Conversely, slower coolings allow iron to locate preferably on the octahedral site, and so aluminum would mainly located at the tetrahedral site. This metal distribution results in higher intensity of the (020) peak when compared to that of (141). Additionally, other transition metals can be incorporated into the brownmillerite structure and its role on the diffraction intensities may be significant (Zotzl and Pollmann 2006).

\section{Sample preparation and data collection}

This subsection is dedicated to two (related) issues. Sample preparation will depend on the data collection strategy as it is not the same to prepare the sample for a $\theta / 2 \theta$ (reflection) experiment that for a transmission measurement. In general, transmission measurements yield more reliable results since more particles are tested. However, the diffracted intensity may be low due to absorption. Furthermore, absorption varies with the diffracted angle and this must be corrected (which is not the case for reflection geometry).

For reflection geometry experiments, the sample surface should be as flat as possible to avoid surface roughness problems in the pattern. However, strong pressing of the sample is not advised as this may lead to preferred orientation. This may be corrected through the March-Dollase ellipsoidal correction (Dollase 1986) but in any case it decreases the amount of information present in a powder pattern. So, preferred orientation should be minimized during sample preparation and corrected during the data analysis stage (to be discussed below). Flat-samples should be rotated during data collection to enhance particle statistics. Reactive samples should be covered with a film (usually Mylar or Kapton) to avoid reaction (for instance carbonation of portlandite) during data collection. Finally, it must be kept in mind that most interiors of X-ray powder diffractometers have very low humidity to avoid/minimize external corrosion of the X-ray tube (for instance we use $\mathrm{P}_{2} \mathrm{O}_{5}$ ). Thus, the surfaces of early-age hydration pastes may be (partially) dehydrated before/during the measurement when kept within the diffractometer. So, we advise to collect the data on pastes as soon as possible or alternatively it is much better to use a reaction/hydration chamber.

For transmission geometry experiments, absorption correction should be carried out for flat samples and capillaries. Additionally, counting time should be large enough to have good statistics in the intensities. Furthermore, the size of the samples (thickness of the flat sample or diameter of the capillary) should be small to have good resolution in the resulting powder pattern. However, very small samples may result in diffraction peak intensity problems as the amount of powder tested by the X-ray may be not fully representative of the sample. Our experience shows that capillaries of $0.3 \mathrm{~mm}$ of diameter (or larger) give good patterns. However, diluted samples in capillaries of $0.3 \mathrm{~mm}$ may start to display problems. Similarly, transmission data for flat samples with thicknesses of the order of 0.2-0.3 mm yield good RQPA results.

Finally, some other issues deserve a brief comment. The data collection range for OPC samples is usually $8-70^{\circ}(2 \theta)$ for $\mathrm{CuK} \alpha$ radiation. The high angle limit is defined by the strong overlapping in the powder pattern and diffraction data above $60^{\circ}(2 \theta)$ add very little extra information to the analysis. However, the low angle region is important mainly in cement analysis as the peaks of $\mathrm{C}_{4} \mathrm{AF}$, gypsum and bassanite should be collected. It is also important to use an optic setup that ensures the X-ray beam is fully within the sample at $10^{\circ}(2 \theta)$. On the other hand it is advisable to have the highest resolution data. This may allow distinguishing between related phases and it also minimizes correlations during the refinement stage. So, strictly monochromatic laboratory data are the best option for a good in-house RQPA. A good alignment of the diffractometer is a pre-requisite and the sample should be mounted exactly on the diffractometer axis to avoid problems in the recorded pattern due to sample displacement. 


\section{Data analysis}

Once the best possible powder pattern has been recorded, Rietveld analysis must be executed with the appropriate program and the control file. Let's us assume that all crystalline phases have structural descriptions and they have been correctly inserted within the control file. This last point is not a trivial statement as sometimes temperature factors are not correctly imported when using automatic structure insertion procedures. Hence, it is a very good practice to check that all structures within the control file have been properly inserted. Furthermore, some space groups have two possible origins but some Rietveld programs only allow the use of one setting.

The Rietveld procedure consists in optimizing several parameters in order to get the best possible agreement between the experimental and the calculated patterns. As a general rule, the structural parameters (atomic positional parameters, atomic temperature factors-also known as atomic displacement parameters since they may have a spatial disorder contribution-and occupation factors) are not generally optimized but they are kept fixed to the reported values. However, the overall parameters (those that affect to the full pattern) are usually optimized. These overall parameters are grouped in sets: i) phase scale factors; ii) background coefficients; iii) zero-shift error or sample displacement parameter; iv) phase unit cell parameters; v) phase peak shape parameters; vi) phase preferred orientation, if needed; vii) sample absorption coefficient (only for capillary or flat-sample transmission data, but the equation correction may depend on the geometry used).

The order in which the parameters should be optimized is always a concern. As a rule of thumb the order should be to start with the parameters which are quite far from the final values, and so proceed adding new parameters which are not that far. We next suggest a sequence which does not need to be always the correct one. Firstly, the phase scale factors and the background coefficients. Secondly, the sample displacement coefficient and the peak shape parameters for the high-content phases. Then, the preferred orientation correction for the phases that display this effect. So, we may continue with the unit cell parameters. Finally, the phase peak shape parameters for low-content phases.

Unfortunately, correlations may be very high for complex refinements and not all parameters may be optimized. Then several tricks may be applied which are somewhat arbitrary but, if they are always applied in the same way, they may give consistent results that allow to establish trends, etc. Now, we must highlight that the overlapping of the main diffraction peaks is a key issue. So, we initially define high-, intermediate- and low-content phases as those present in the sample at contents higher than $20 \mathrm{wt} \%$, between $5-20 \mathrm{wt} \%$ and lower than $5 \mathrm{wt} \%$. However, these "labels" will certainly depend upon the degree of peak overlapping. For instance, a phase present in a sample at $2 \mathrm{wt} \%$ but with narrow peaks and little overlapping may be considered as intermediate-content phase, and conversely, a phase at $9 \mathrm{wt} \%$ level but with very strong overlapping may be considered as a low-content one. For high-content phases every parameter may be refined included at least two coefficients for the peak shape (both Gaussian and Lorentzian contributions when using a pseudo-Voigt peak shape function). For intermediate-content phase, dumping (cushioning) values should be quite high. Furthermore, overlapping may not allow optimizing two peak shape parameters. Then one value should be kept fix to a reasonable value and just refine one (and check that it does not get a very large, unreasonable, value). Finally, unit cell parameters and peak shape coefficients may be quite difficult to optimize for low-content phases. They should be refined with extreme care or kept fixed to goods values. For instance, they may be kept to the refined values in selective dissolution residues where their contents were much higher. If these residues are not available, the experience in previous fits uses to be a very good asset.

Preferred orientation (a partial microparticle aligned arrangement) deserves a final comment. Working in reflection geometry, sample rotation increases the particle statistics 
but it does not minimize preferred orientation. This effect is shown up in the Rietveld fit of the powder pattern as some peaks having smaller calculated intensities meanwhile other reflections having larger calculated intensities. In order to correct this effect with the MarchDollase algorithm, the preferred orientation axis (corresponding to the cleavage plane or a main growth axis) must be inserted in the Rietveld control file. We next give the axes for some phases showing this effect. However, it must be highlighted that preferred orientation strongly depends on the microparticle habits that may vary according to the synthetic conditions. The axes for some phases are: gypsum [010]; portlandite [001]; AFm [001]; calcite [104]; alite- $\mathrm{M}_{3}$ [101]; and ettringite [100].

\section{Final check}

After a RQPA is carried out two final checks are advisable. The first is to ensure that the refined parameters have not converged to unreasonable values. This may be avoided if a higher and lower limit is set up for each adjustable parameter. This is the strategy for on-line fully automatic RQPA in many cement plants where robustness is ensured even although some parameters are not allowed to vary totally free. Phase peak shape parameters are the most critical variables and they should be kept under permanent surveillance. The final values of the unit cell parameters for low-content phases should also be examined with care.

Secondly, it is very important to compare the RQPA results with others obtained from complementary techniques, if possible. A previous section was devoted to this issue, so it is not further treated here. However, a lot of confidence is gained when RQPA results are successfully compared with other analytical results (for instance portlandite content determined from thermal analysis).

\section{FINAL REMARKS AND OUTLOOK}

Rietveld quantitative phase analysis is being increasingly used for characterizing OPC materials. Initially, it was mainly devoted to measure anhydrous cements but it is nowadays being used a lot for analyzing hydration products. It is clear that RQPA will be used for studying the hydration reactions of many blended cements. The number of residues, by-products, etc. (with different chemical and mineralogical compositions) that can be blended with Portland cements is quite large, and expanding.

In addition, new types of eco-cements, those releasing less $\mathrm{CO}_{2}$ in their fabrication processes, are being deeply investigated. Here, RQPA has a bright future as most of the knowhow developed for characterizing OPC samples can be directly exported to analyze these new cements (calcium sulfoaluminate, sufobelite, alkali-activated fly ash or slag, etc.).

In addition to the (new) cements to be studied, some theoretical/methodological advances are expected. Firstly, some advances concerning the crystal structures will be very welcomed: i) Reporting new crystal structures as some phases have not reported structures that must be developed for RQPA (e.g., the crystal structure of $\mathrm{C}_{2} \mathrm{AH}_{8}$ is lacking); ii) Obtaining better structural descriptions for some phases, which have approximate crystal structures, in order to have more accurate phase analyses (e.g., a good structural description at room temperature for $\alpha-C_{2} S$ is lacking); iii) when several structural descriptions for one phase are available, some (ideally inter-laboratory) comparative studies should be carried out to select the most adequate crystal structure to carry out the RQPA.

Another field where progress is expected is increasing the reliability of the diffraction data. This improvement can be obtained at least in two ways. One approach is to carry out a better microparticle sampling by using higher-energy Mo-radiation. To the best of our knowledge, there is not a single reported RQPA of OPC material with Mo-radiation. This is likely due to the lower resolution from existing powder diffractometers. Figure 9 shows the Rietveld fits of 


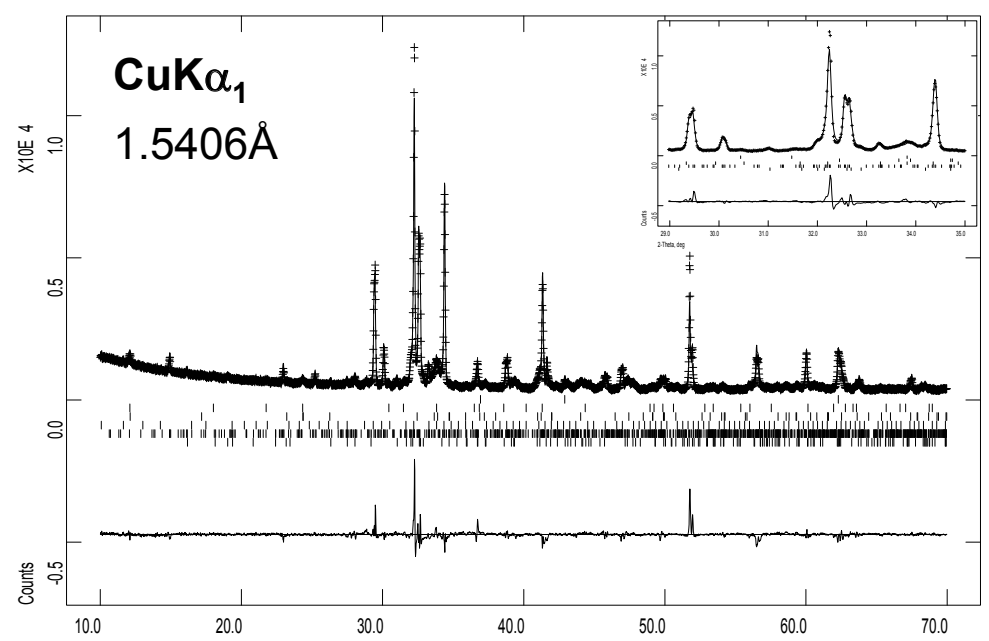

2-Theta, deg

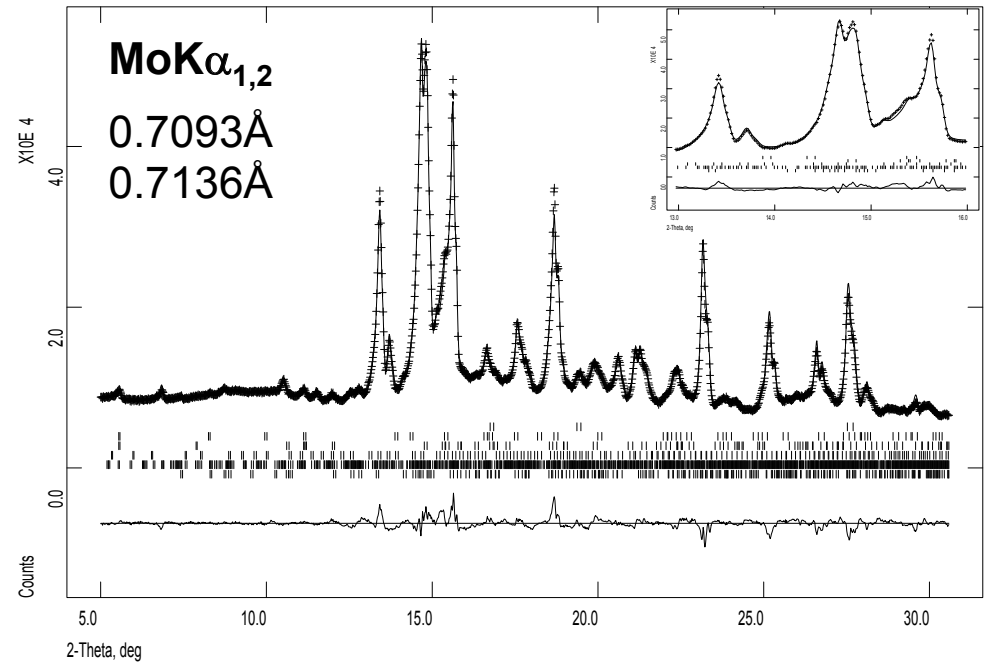

Figure 9. (top) Full region of a Rietveld plot of high-resolution $\mathrm{CuK} \alpha_{1}$ laboratory data in reflection geometry for a commercial OPC grey clinker with 6 phases, from bottom to top: belite, alite, aluminate, ferrite, aphthitalite and periclase. (bottom) Full region of a Rietveld plot of medium-resolution MoK $\alpha_{1,2}$ laboratory data in reflection geometry for the same clinker. The insets show enlarged views of the common $2 \theta$ range, $29-35^{\circ}$ for the $\mathrm{Cu}$-pattern and $12.9-16.2^{\circ}$ for the Mo-pattern.

a grey OPC clinker where the phase analysis has been carried out fitting simultaneously a high resolution $\mathrm{CuK} \alpha_{1}$ pattern collected in reflection geometry and a medium-resolution $\mathrm{MoK} \alpha_{1,2}$ pattern also collected in reflection geometry. The phase analysis obtained fitting both patterns simultaneously was: $\mathrm{C}_{3} \mathrm{~S}-\mathrm{M}_{3}, 69.6(7) \mathrm{wt} \% ; \beta-\mathrm{C}_{2} \mathrm{~S}, 15.3(1) \mathrm{wt} \% ; \mathrm{C}_{3} \mathrm{~A}$-cubic, 4.4(2) wt \%; $\mathrm{C}_{4} \mathrm{AF}, 9.0(1) \mathrm{wt} \%$; $\mathrm{MgO}, 0.86(1) \mathrm{wt} \%$; and $\mathrm{K}_{3} \mathrm{Na}\left(\mathrm{SO}_{4}\right)_{2}, 0.84(2) \mathrm{wt} \%$. The large penetration depth of Mo-K $\alpha$ radiation has two consequences on the alite quantification. Firstly, many more particles are analyzed when irradiated with high energy wavelengths 0.7093 and 0.7136 $\AA$. So, alite peaks are nicely fitted in the Mo-K $\alpha$ pattern, meanwhile the fit is much worse for the $\mathrm{Cu}-\mathrm{K} \alpha$ pattern (due to a poorer particle statistics). Furthermore, preferred orientation (along [ $\overline{1} 01]$ axis of alite-M $M_{3}$ ) is also less important in the Mo-K $\alpha$ pattern. The March-Dollase 
optimized coefficients were $0.855(3)$ and $0.961(2)$ for the $\mathrm{Cu}-\mathrm{K} \alpha_{1}$ and $\mathrm{Mo}-\mathrm{K} \alpha_{1,2}$ patterns, respectively. However, the resolution of the Mo-pattern is not very good (see inset of Fig. 9, bottom) and better equipment is expected in the near future, including the key development of a primary monochromator for laboratory Mo-K $\alpha$ radiation.

A second approach is to increase the accuracy of the RQPA results by combining at least two data sets. For instance, it is possible to carry out a RQPA for a single sample but from two data sets, e.g., one high-resolution powder data collected in reflection and a second pattern collected in transmission in order to have a better powder averaging although the resolution of the diffraction peaks may be lower. Figure 10 shows the Rietveld fits of calcium
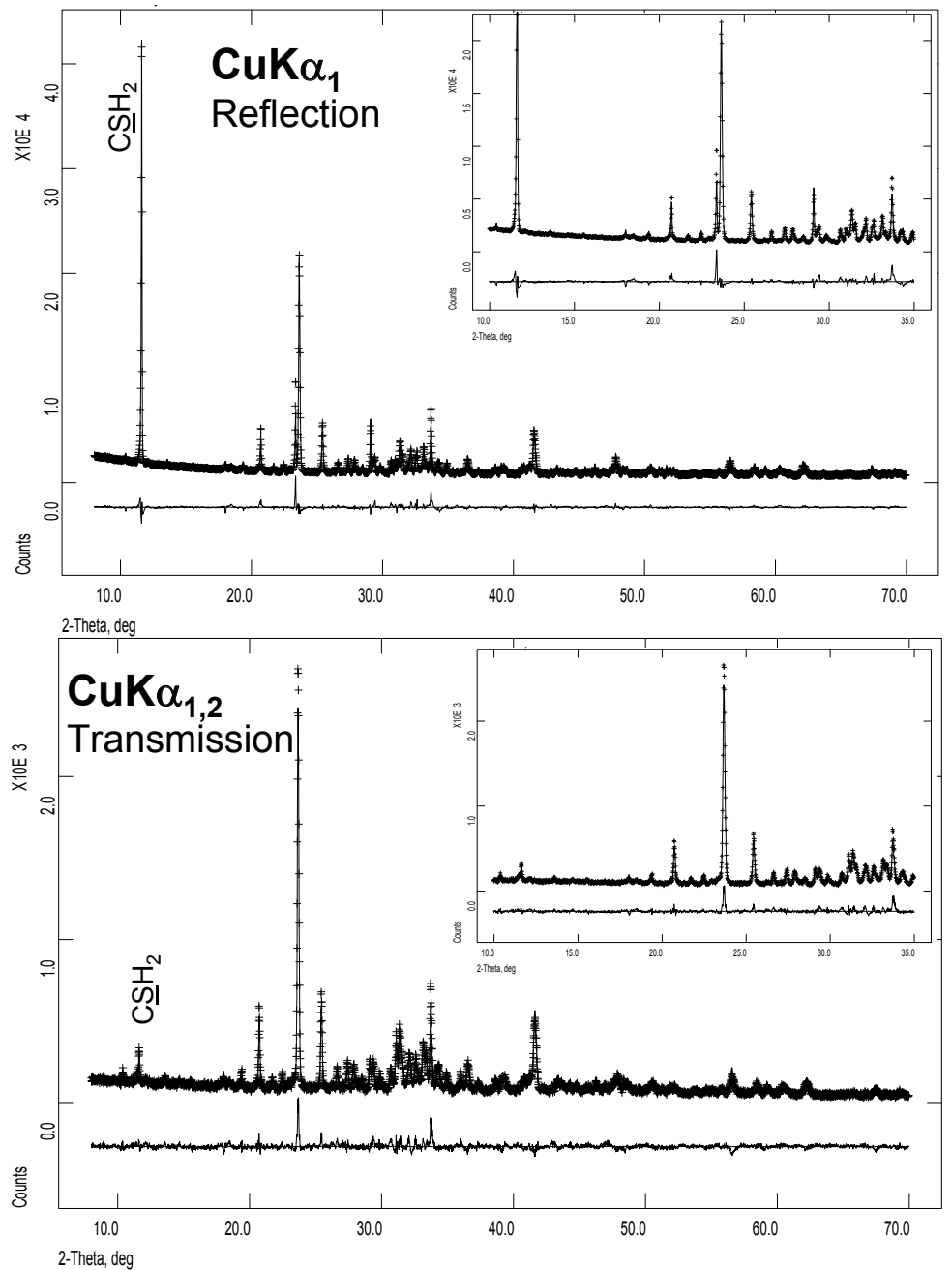

Figure 10. (top) Full region of a Rietveld plot of high-resolution CuK $\alpha_{1}$ laboratory data collected in reflection geometry for a calcium sulfoaluminate cement containing nine crystalline phases. (bottom) Full region of a Rietveld plot of medium-resolution $\mathrm{CuK \alpha _{1,2 }}$ laboratory data collected in transmission geometry for the same calcium sulfoaluminate. The insets show enlarged views of the low-angle regions to highlight the effects of the gypsum preferred orientation. 
sulfoaluminate cement where the phase analysis has been carried out fitting simultaneously a high resolution pattern collected in reflection and a medium-resolution pattern collected in transmission. We must highlight that both fits are carried out with a final gypsum optimized content of 13.5(1) wt\% but the March-Dollase preferred orientation correction coefficients were $0.499(8)$ and $1.37(2)$ for the reflection and transmission patterns, respectively. This cement has a very complex phase assemblage formed by: cubic-Yeelimite, $\mathrm{Ca}_{4} \mathrm{Al}_{6} \mathrm{O}_{12} \mathrm{SO}_{4}$, 23.6(2) wt \%; orthorhombic-Yeelimite, 15.9(2) wt \%; ternesite, $\mathrm{Ca}_{5}\left(\mathrm{SiO}_{4}\right)_{2} \mathrm{SO}_{4}, 16.7(3) \mathrm{wt} \%$; gypsum, 13.5(1) wt \%; $\beta$-belite, 9.9(1) wt\%; anhydrite-II, 8.3(1) wt $\%$; alite- $\mathrm{M}_{3}, 6.1(1) \mathrm{wt} \%$; calcium titanium perovkskite, $\mathrm{CaTiO}_{3}, 4.7(1) \mathrm{wt} \%$; and dolomite, $(\mathrm{Mg}, \mathrm{Ca}) \mathrm{CO}_{3}, 1.2(1) \mathrm{wt} \%$. RQPA results obtained from the simultaneous two-histogram refinement is more accurate that using just one single dataset.

Finally, we expect to see a large increase of the use of the external standard method in hydration products analyses. This approach which still is not very common has two clear advantages over the internal standard (spiking) method as i) no dilution of low content phases takes place, and ii) the (possible) interference of the standard with the hydration reactions is avoided.

\section{ACKNOWLEDGMENTS}

This work has been supported by Spanish Ministry of Science and Innovation through the MAT2010-16213 research grant which is co-funded by FEDER. We also thank Junta de Andalucía (Spain) for funding through the FQM-113 project.

\section{REFERENCES}

Allmann R (1977) Refinement of the hybrid layer structure $\left(\mathrm{Ca}_{2} \mathrm{Al}(\mathrm{OH})_{6}\right)^{+}\left(0.5 \mathrm{SO}_{4} \cdot 3 \mathrm{H}_{2} \mathrm{O}\right)$. Neues Jahrb Mineral Monatsh 136-144

Ballirano P, Belardi G, Maras A (2005) Refinement of the structure of synthetic syngenite $\mathrm{K}_{2} \mathrm{Ca}\left(\mathrm{SO}_{4}\right)_{2}\left(\mathrm{H}_{2} \mathrm{O}\right)$ from X-ray powder diffraction data. Neues Jahrb Mineral Abh 182:15-21

Balonis M, Glasser FP (2009) The density of cement phases. Cem Concr Res 39:733-739

Balonis M, Lothenbach B, Le Saout G, Glasser FP (2010) Impact of chloride on the mineralogy of hydrated Portland cement systems. Cem Concr Res 40:1009-1022

Balzar D, Audebrand N, Daymond MR, Fitch A, Hewat A, Langford JI, Le Bail A, Louer D, Masson O, McCowan CN, Popa NC, Stephens PW, Toby BH (2004) Size-strain line-broadening analysis of the ceria round-robin sample. J Appl Crystallogr 37:911-924

Barnett SJ, Macphee DE, Lachowski EE, Crammond NJ (2002) XRD, EDX and IR analysis of solid solutions between thaumasite and ettringite. Cem Concr Res 32:719-730

Bellmann F, Damidot D, Moser B, Skibsted J (2010) Improved evidence for the existence of an intermediate phase during hydration of tricalcium silicate. Cem Concr Res 40:875-884

Ben-Haha M, De Weerdt K, Lothenbach B (2010) Quantification of the degree of reaction of fly ash. Cem Concr Res 40:1620-1629

Bentz DP (2008) A review of early-age properties of cement-based materials. Cem Concr Res 38:196-204

Bezou C, Nonat A, Mutin JC, Christensen AN, Lehmann MS (1995) Investigation of the crystal structure of gamma-CaSO${ }_{4}, \mathrm{CaSO}_{4} \cdot 0.5\left(\mathrm{H}_{2} \mathrm{O}\right)$ and $\mathrm{CaSO}_{4} \cdot 0.6\left(\mathrm{H}_{2} \mathrm{O}\right)$ by powder diffraction methods. J Solid State Chem 117:165-176

Bish DL, Howard SA (1988) Quantitative phase analysis using the Rietveld method. J Appl Crystallogr 21:8691

Bish DL, Post JE (1993) Quantitative mineralogical analysis using the Rietveld full-pattern fitting method. Am Mineral 78:932-940

Bish DL, Post JE (eds) (1989) Modern Powder Diffraction. Reviews in Mineralogy. Vol 20. Mineralogical Society of America, Washington

Bish DL, Reynolds RC Jr (1989) Sample preparation for X-ray diffraction. Rev Mineral 20:73-99

Blaine R (1995) Determination of calcium-sulfate hydrates in building-materials using thermal-analysis. Am Lab 27:24-28

Bogue RH (1929) Calculation of the compounds in Portland cement. Ind Eng Chem 1:192-197 
Bonaccorsi E, Merlino S, Kampf AR (2005) The crystal structure of Tobermorite $14 \AA$ (Plombierite), a C-S-H phase. J Am Ceram Soc 88:505-512

Bonaccorsi E, Merlino S, Taylor HFW (2004) The crystal structure of jennite $\mathrm{Ca}_{9} \mathrm{Si}_{6} \mathrm{O}_{18}(\mathrm{OH})_{6} \cdot 8 \mathrm{H}_{2} \mathrm{O}$. Cem Concr Res 34:1481-1488

Brindley GW (1945) The effect of grain or particle size on X-ray reflections from mixed powders and alloys, considered in relation to the quantitative determination of crystalline substances by X-ray methods. Philos Mag 36:347-369

Brunet F, Charpentier T, Chao CN, Peycelon H, Nonat A (2010) Characterization by solid-state NMR and selective dissolution techniques of anhydrous and hydrated CEM V cement pastes. Cem Concr Res 40:208-219

Buhrke VE, Jenkins R, Smith DK (1998) A Practical Guide for the Preparation of Specimens for X-Ray Fluorescence and X-Ray Diffraction Analysis. Wiley-VCH, New York

Calos NJ, Kennard CHL, Whittaker AK, Davis RL (1995) Structure of calcium aluminate sulfate $\mathrm{Ca}_{4} \mathrm{Al}_{6} \mathrm{O}_{16} \mathrm{~S}$. J Solid State Chem 119:1-7

Campbell DH (1999) Microscopical Examination and Interpretation of Portland Cement and Clinker. Second Edition. Portland Cement Association. Skokie

Campbell DH, Galehouse JS (1991) Quantitative clinker microscopy with the light microscope. Cem Concr Aggr 13:94-96

Castellote M, Alonso C, Andrade C, Turrillas X, Campo J (2004) Composition and microstructural changes of cement pastes upon heating, as studied by neutron diffraction. Cem Concr Res 34:1633-1644

Castellote M, Andrade C, Turrillas X, Campo J, Cuello G (2008) Accelerated carbonation of cement pastes in situ monitored by neutron diffraction. Cem Concr Res 38:1365-1373

Chen IA, Juenger MCG (2009a) Incorporation of waste materials into Portland cement clinker synthesized from natural raw materials. J Mater Sci 44:2617-2627

Chen IA, Juenger MCG (2009b) Incorporation of waste materials into Portland cement clinker synthesized from reagent-grade chemicals. Int J Appl Ceram Technol 6:270-278

Cheung J, Jeknavorian A, Roberts L, Silva D (2011) Impact of admixtures on the hydration kinetics of Portland cement. Cem Concr Res 41:1289-1309

Christensen AN, Olesen M, Cerenius Y, Jensen TR (2008) Formation and transformation of five different phases in the $\mathrm{CaSO}_{4}-\mathrm{H}_{2} \mathrm{O}$ system: crystal structure of the subhydrate $\beta-\mathrm{CaSO}_{4} \cdot 0.5 \mathrm{H}_{2} \mathrm{O}$ and soluble anhydrite $\mathrm{CaSO}_{4}$. Chem Mater 20:2124-2132

Cline JP, Von Dree RB, Winburn R, Stephens PW, Filliben JJ (2011) Addressing the amorphous content issue in quantitative phase analysis: the certification of NIST standard reference material 676a. Acta Crystallogr Sect A 67:357-367

Colville AA, Géller S (1971) The crystal structure of brownmillerite, $\mathrm{Ca}_{2} \mathrm{FeAlO}_{5}$. Acta Crystallogr B27:23112315

Crumbie A, Walenta G, Fuellmann T (2006) Where is the iron? Clinker microanalysis with XRD Rietveld, optical microscopy/point counting, Bogue and SEM-EDS techniques. Cem Concr Res 36:1542-1547

Cullity BD (1978) Elements of X-Ray Diffraction. Addison-Wesley, Reading, Massachusetts

Dalconi MC, Favero M, Aritoli G (2011) In-situ XRPD of hydrating cement with lab instrument: reflection vs. transmission measurements. Z Kristallogr Proc 1:155-161

Damidot D, Lothenbach B, Herfort D, Glasser FP (2011) Thermodynamics and cement science. Cem Concr Res 41:679-695

David WIF, Shankland K (2008) Structure determination from powder diffraction data. Acta Crystallogr 64:5264

David WIF, Shankland K, McCusker LB, Baerlocher Ch (2002) Structure Determination from Powder Diffraction Data. International Union of Crystallography Monographs on Crystallography. Oxford University Press, Oxford

De la Torre AG, Alonso-Llorente H, Aranda MAG, León-Reina L (2011) Últimas novedades en la aplicación del método de Rietveld en el control de calidad de cementos. Cemento Hormigón 944:16-27

De la Torre AG, Aranda MAG (2003) Accuracy in Rietveld quantitative phase analysis of Portland cements. J Appl Crystallogr 36:1169-1176

De la Torre AG, Bruque S, Aranda MAG (2001a) Rietveld quantitative amorphous content analysis. J Appl Crystallogr 34:196-202

De la Torre AG, Bruque S, Aranda MAG (2003) Cuantificación mineralógica directa de cementos Portland por el método de Rietveld. Cemento Hormigón 850:16-27

De la Torre AG, Bruque S, Campo J, Aranda MAG (2002) The superstructure of $\mathrm{C}_{3} \mathrm{~S}$ from synchrotron and neutron powder diffraction and its role in quantitative phase analyses. Cem Concr Res 32:1347-1356

De la Torre AG, Cabeza A, Calvente A, Bruque S, Aranda MAG (2001b) Full phase analysis of Portland clinker by penetrating synchrotron powder diffraction. Anal Chem 73:151-156 
De la Torre AG, Cabeza A, Losilla ER, Aranda MAG (2006) Quantitative phase analysis of ordinary Portland cements using synchrotron radiation powder diffraction. Z Kristallogr Sup 23:587-592

De la Torre AG, de Vera RN, Cuberos AJM, Aranda MAG (2008) Crystal structure of low-magnesium content alite: application to Rietveld quantitative phase analysis. Cem Concr Res 38:1261-1269

De la Torre AG, Lopez-Olmo MG, Alvarez-Rua C, Garcia-Granda S, Aranda MAG (2004) Structure and microstructure of gypsum and its relevance to Rietveld quantitative phase analyses. Powder Diffr 19:240246

De la Torre AG, Losilla ER, Cabeza A, Aranda MAG (2005) High-resolution synchrotron powder diffraction analysis of ordinary Portland cements: Phase coexistence of alite. Nucl Instrum Methods Phys ResB 238:87-91

De Weerdt K, Haha MB, Le Saout G, Kjellsen KO, Justnes H, Lothenbach B (2011) Hydration mechanisms of ternary Portland cements containing limestone powder and fly ash. Cem Concr Res 41:279-291

Dinnebier RE, Billinge SJL (eds) (2008) Powder Diffraction Theory and Practice. Royal Society of Chemistry Publishing, Cambridge

Dollase WA (1986) Correction of intensities for preferred orientation in powder diffractometry: application of the March model. J Appl Crystallogr 19:267-272

Dyson HM, Richardson IG, Brough AR (2007) A combined ${ }^{29}$ Si MAS NMR and selective dissolution technique for the quantitative evaluation of hydrated blast furnace slag cement blends. J Am Ceram Soc 90:598-602

Effenberger H, Kirfel A, Will G (1983a) Studies of the electron-density distribution of dolomite, $\mathrm{CaMg}\left(\mathrm{CO}_{3}\right)_{2}$. Tscher Mineral Petrogr Mitteil 31:151-164

Effenberger H, Kirfel A, Will G, Zobetz E (1983b) A further refinement of the crystal structure of thaumasite, $\mathrm{Ca}_{3} \mathrm{Si}(\mathrm{OH})_{6}\left(\mathrm{CO}_{3}\right)\left(\mathrm{SO}_{4}\right)\left(\mathrm{H}_{2} \mathrm{O}\right)_{12}$. Neues Jb Mineral Monatsh 60-68

Elton NJ, Salt PD (1996) Particle statistics in quantitative X-ray diffractometry. Powder Diffr 11:218-229

Enders M (2005) Sample preparation for quantitative X-ray diffraction in cement plants: sources of errors and solutions. ZKG Int 58:28-37

Enders M, Berger M (2007) Quantitative XRD (Rietveld-method) in cement plants: quality control of clinker production. ZKG Int 5:50-59

Ferreira AV, Righi A, Araujo FGS, Espinosa DCR, Tenório JAS (2008) Applications of the Rietveld method to quantify the crystalline phases of Portland cement clinker doped with nickel and chromium. Powder Diffr Suppl 23:S42-S45

Ferro O, Galli E, Papp G, Quartieri S, Szakall S, Vezzalini G (2003) A new occurrence of katoite and reexamination of the hydrogrossular group. Eur J Mineral 15:419-426

Fitzpatrick ME, Lodini A (eds) (2003) Analysis of Residual Stress by Diffraction using Neutron and Synchrotron Radiation. Taylor \& Francis, London

Fleet ME (1984) The structure of magnetite: two annealed natural magnetites, $\mathrm{Fe}_{3.005} \mathrm{O}_{4}$ and $\mathrm{Fe}_{2.96} \mathrm{Mg}_{0.04} \mathrm{O}_{4}$. Acta Crystallogr C40:1491-1493

Floerke OW (1952) Kristallographische und rontgenometrische Untersuchungen im System $\mathrm{CaSO}_{4}$ $\mathrm{CaSO}_{4} \cdot 2 \mathrm{H}_{2} \mathrm{O}$. Neues Jahrb Miner Abh 84:189-240

Francois M, Renaudin G,EvrardO(1998)A cementitious compound with composition $3 \mathrm{CaOAl}_{2} \mathrm{O}_{3} \mathrm{CaCO}_{3} 11 \mathrm{H}_{2} \mathrm{O}$. Acta Crystallogr C 54:1214-1217

Fullmann T, Walenta G (2003) The quantitative Rietveld phase analysis in industrial applications. ZKG Int 56:45-53

Gemmi M, Merlini M, Cruciani G, Artioli G (2007) Non-ideality and defectivity of the akermanite - gehlenite solid solution: an X-ray diffraction and TEM study. Am Mineral 92:1685-1694

Gineys N, Aouad G, Sorrentino F, Damidot D (2011) Incorporation of trace elements in Portland cement clinker: Thresholds limits for $\mathrm{Cu}, \mathrm{Ni}, \mathrm{Sn}$ or $\mathrm{Zn}$. Cem Concr Res 41:1177-1184

Gobbo L, Sant'Agostino L, Garcez L (2004) $\mathrm{C}_{3}$ A polymorphs related to industrial clinker alkalies content. Cem Concr Res 34:657-664

Goetz-Neunhoeffer F, Neubauer J (2006) Refined ettringite $\left(\mathrm{Ca}_{6} \mathrm{Al}_{2}\left(\mathrm{SO}_{4}\right)_{3}(\mathrm{OH})_{12} \cdot 26\left(\mathrm{H}_{2} \mathrm{O}\right)\right)$ structure for quantitative X-ray diffraction analysis. Powder Diffr 21:4-11

Golovastikov NI, Matveeva RG, Belov NV (1975) Crystal structure of the tricalcium silicate $\left(\mathrm{CaOSi}_{2}\right)_{3}=\mathrm{C}_{3} \mathrm{~S}$. Kristallografiya 20:721-729

Gonçalves JP, Tavares LM, Toledo-Filho RD, Fairbairn EMR (2009) Performance evaluation of cement mortars modified with metakaolin or ground brick. Const Build Mater 23:1971-1979

Grattan-Bellew PE, Mitchell LD, Margeson J, Minb D (2010) Is alkali-carbonate reaction just a variant of alkali-silica reaction ACR $=$ ASR? Cem Concr Res 40:556-562

Gutteridge WA (1979) On the dissolution of the interstitial phases in Portland cement. Cem Concr Res 9:319324

Gutteridge WA (1984) Quantitative X-ray powder diffraction in the study of some cementive materials. Brit Ceram Proc 35:11-23 
Herfort D, Moir GK, Johansen V, Sorrentino F, BolioArceo H (2010) The chemistry of Portland cement clinker. Adv Cem Res 22:187-194

Hesse C, Degenkolb M, Gaeberlein P, Goetz-Neunhoeffer F, Neubauer J, Schwarz V (2008) Investigations into the influence of temperature and w/c ratio on the early hydration of white cement. Cem Int 6:68-78

Hesse C, Goetz-Neunhoeffer F, Neubauer J (2011) A new approach in quantitative in-situ XRD of cement pastes: Correlation of heat flow curves with early hydration reactions. Cem Concr Res 41:123-128

Hesse C, Goetz-Neunhoeffer F, Neubauer J, Braeu M, Gaeberlein P (2009) Quantitative in situ X-ray diffraction analysis of early hydration of Portland cement at defined temperatures. Powder Diffr 24:112-115

Hesse KF (1984) Refinement of the crystal structure of wollastonite-2M (parawollastonite). Zeit Kristallogr 168:93-98

Hill RJ, Howard CJ (1987) Quantitative phase analysis from neutron powder diffraction data using the Rietveld method. J Appl Crystallogr 20:467-474

Hong H, Fu Z, Min X (2001) Effect of cooling performance on the mineralogical character of Portland cement clinker. Cem Concr Res 31:287-290

Hoshino S, Yamada K, Hirao H (2006) XRD/Rietveld Analysis of the Hydration and Strength Development of Slag and Limestone Blended Cement. J Adv Concr Tech 4:357-367

Husillos-Rodriguez N, Martinez-Ramirez S, Blanco-Varela MT, Guillem M, Puig J, Larrotcha E, Flores J (2010) Re-use of drinking water treatment plant (DWTP) sludge: Characterization and technological behaviour of cement mortars with atomized sludge additions. Cem Concr Res 40:778-786

Irran E, Tillmanns E, Hentschel $\mathrm{G}$ (1997) Ternesite, $\mathrm{Ca}_{5}\left(\mathrm{SiO}_{4}\right)_{2} \mathrm{SO}_{4}$, a new mineral from the Ettringer Bellerberg/Eifel, Germany. Mineral Petrol 60:121-132

Jansen D, Bergold ST, Goetz-Neunhoeffer F, Neubauer J (2011b) The hydration of alite: a time-resolved quantitative X-ray diffraction approach using the G-factor method compared with heat release. J Appl Crystallogr 44:895-901

Jansen D, Goetz-Neunhoeffer F, Lothenbach B, Neubauer J (2012a) The early hydration of Ordinary Portland Cement (OPC): An approach comparing measured heat flow with calculated heat flow from QXRD. Cem Concr Res 42:134-138

Jansen D, Neubauer J, Goetz-Neunhoeffer F, Haerzschel R, Hergeth WD (2012b) Change in reaction kinetics of a Portland cement caused by a superplasticizer - Calculation of heat flow curves from XRD data. Cem Concr Res 42:327-332

Jansen D, Stabler CH, Goetz-Neunhoeffer F, Dittrich S, Neubauer J (2011a) Does Ordinary Portland Cement contain amorphous phase? A quantitative study using an external standard method. Powder Diffr 26:3138

Jenkins R, Fawcett TG, Smith DK, Visser JW, Morris MC, Frevel LK (1986) JCPDS-international centre for diffraction data sample preparation methods in X-Ray Powder Diffraction. Powder Diffr 1:51-63

Jenkins R, Snyder RL (1996) Introduction to X-Ray Powder Diffractometry. Wiley-Interscience, New York

Jupe AC, Wilkinson AP, Luke K, Funkhouser GP (2007) Slurry consistency and in situ synchrotron X-ray diffraction during the early hydration of portland cements with calcium chloride. J Am Ceram Soc 90:2595-2602

Kaduk JA (2007a) Chemical reasonableness in Rietveld analysis: organics. Powder Diffr 22:74-82

Kaduk JA (2007b) Chemical reasonableness in Rietveld analysis: inorganics. Powder Diffr 22:268-278

Katsioti M, Patsikas N, Pipilikaki P, Katsiotis N, Mikedi K, Chaniotakis M (2011) Delayed ettringite formation (DEF) in mortars of white cement. Constr Build Mater 25:900-905

Kholer S, Heinz D, Urbonas L (2006) Effect of ettringite on thaumasite formation. Cem Concr Res 36:697-706

Kirfel A, Will G (1980) Charge density in anhydrite, $\mathrm{CaSO}_{4}$, from X-ray and neutron diffraction. Acta Crystallogr B36:2881-2890

Klug HP, Alexander LE (1974) X-Ray Diffraction Procedures. Wiley-Interscience, New York

Korpa A, Kowald T, Trettin R (2009) Phase development in normal and ultra-high performance cementitious systems by quantitative X-ray analysis and thermoanalytical methods. Cem Concr Res 39:69-76

Kumar S, Kumar R, Bandopadhyay A, Alex TC, Ravi-Kumar B, Das SK, Mehrotra SP (2008) Mechanical activation of granulated blast furnace slag and its effect on the properties and structure of Portland slag cement. Cem Concr Res 30:679-685

Lager GA, Armbruster Th, Faber J Jr (1987) Neutron and X-ray diffraction study of hydrogarnet $\mathrm{Ca}_{3} \mathrm{Al}_{2}\left(\mathrm{O}_{4} \mathrm{H}_{4}\right)_{3}$. Am Mineral 72:756-765

Larson AC, Von Dreele RB (1994) Los Alamos National Lab. Rep. No. LA-UR-86-748, Los Alamos

Le Saout, Fullmann T, Kocaba V, Scrivener K (2007) Quantitative study of cementitious materials by X-ray diffraction/Rietveld analysis using an external standard. In: Proceedings of $12^{\text {th }}$ International Congress on the Chemistry of Cement (ICCC2007), July 8-13, 2007, Montréal, Canada. 12 pages

Le Saout, Kocaba V, Scrivener K (2011) Application of the Rietveld method to the analysis of anhydrous cements. Cem Concr Res 41:133-148 
Leoni M, Scardi P, Pelosato R, Sora IN, Dotelli G, Stampino PG, Presti AL (2007) Phase composition gradient in leached polluted cement monoliths. Cem Concr Res 37:1483-1495

León-Reina L, De la Torre AG, Porras-Vázquez JM, Cruz M, Ordonez LM, Alcobé X, Gispert-Guirado F, Larranaga-Varga A, Paul M, Fuellmann T, Schmidt R, Aranda MAG (2009) Round robin on Rietveld quantitative phase analysis of Portland cements. J Appl Crystallogr 42:906-916

Lothenbach B, Matschei T, Möschner G, Glasser FP (2008a) Thermodynamic modelling of the effect of temperature on the hydration and porosity of Portland cement. Cem Concr Res 38:1-18

Lothenbach B, Le Saout G, Gallucci E, Scrivener K (2008b) Influence of limestone on the hydration of Portland cements. Cem Concr Res 38:848-860

Lothenbach B, Scrivener K, Hooton RD (2011) Supplementary cementitious materials. Cem Concr Res 41:217-229

Lothenbach B, Winnefeld F (2006) Thermodynamic modelling of the hydration of Portland cement. Cem Concr Res 36:209-226

Louisnathan SJ (1971) Refinement of the crystal structure of a natural gehlenite, $\mathrm{Ca}_{2} \mathrm{Al}(\mathrm{Al}, \mathrm{Si}) \mathrm{O}_{7}$. Can Mineral 10:822-837

Luke K, Glasser FP (1987) Selective dissolution of hydrated blast furnace slag cements. Cem Concr Res 17:273-282

Lundgaard N, Jons ES (2003) Quantitative Rietveld XRD Analysis. World Cem 34:59-63

Madsen IC, Scarlett NVI (2008) Quantitative Phase Analysis. In: Powder Diffraction Theory and Practice. Dinnebier RE, Billinge SJL (eds). Royal Society of Chemistry Publishing, Cambridge, p 298-331

Madsen IC, Scarlett NVY, Cranswick LMD, Lwin T (2001) Outcomes of the International Union of Crystallography Commission on powder diffraction round robin on quantitative phase analysis: samples 1a to 1h. J Appl Crystallogr 34:409-426

Makar JM, Chan GW (2008) End of the induction period in ordinary Portland cement as examined by highresolution scanning electron microscopy. J Am Ceram Soc 91:1292-1299

Maltese C, Pistolesi C, Bravo A, Cella F, Cerulli T, Salvioni D (2007) A case history: effect of moisture on the setting behaviour of a Portland cement reacting with an alkali-free accelerator. Cem Concr Res 37:856865

Manias C, Madsen IC, Retallack D (2001) Plant optimisation and control using continuous on-line XRD for mineral phase analysis. ZKG Int 54:138-145

Marinoni N, Pavese A, Voltolini M, Merlini M (2008) Long-term leaching test in concretes: an X-ray powder diffraction study. Cem Concr Comp 30:700-705

Markvardsen AJ, Shankland K, David, WIF, Johnston JC, Ibberson, RM, Tucker M, Nowell, H, Griffin T (2008) ExtSym: a program to aid space-group determination from powder diffraction data. J Appl Crystallogr 41:1177-1181

Maslen EN, Streltsov VA, Streltsova NR, Ishizawa N (1995) Electron density and optical anisotropy in rhombohedral carbonates. III. Synchrotron X-ray studies of $\mathrm{CaCO}_{3}, \mathrm{MgCO}_{3}$ and $\mathrm{MnCO}_{3}$. Acta Crystallogr B51:929-939

Matschei T, Glasser FP (2010) Temperature dependence, 0 to $40{ }^{\circ} \mathrm{C}$, of the mineralogy of Portland cement paste in the presence of calcium carbonate. Cem Concr Res 40:763-777

Matschei T, Lothenbach B, Glasser FP (2007a) The AFm phase in Portland cement. Cem Concr Res 37:118130

Matschei T, Lothenbach B, Glasser FP (2007b) Thermodynamic properties of Portland cement hydrates in the system $\mathrm{CaO}-\mathrm{Al}_{2} \mathrm{O}_{3}-\mathrm{SiO}_{2}-\mathrm{CaSO}_{4}-\mathrm{CaCO}_{3}-\mathrm{H}_{2} \mathrm{O}$. Cem Concr Res 37:1379-1410

McCusker LB, Von Dreele RB, Cox DE, Louer D, Scardi P (1999) Rietveld refinement guidelines. J Appl Crystallogr 32:36-50

Merlini M, Artioli G, Cerulli T, Cella F, Bravo A (2008) Tricalcium aluminate hydration in additivated systems. A crystallographic study by SR-XRPD. Cem Concr Res 38:477-486

Merlini M, Artioli G, Meneghini C, Cerulli T, Bravo A, Cella F (2007b) The early hydration and the set of Portland cements: in situ X-ray powder diffraction studies. Powder Diffr 22:201-208

Merlini M, Meneghini C, Artioli G, Cerulli T (2007a) Synchrotron radiation XRPD study on the early hydration of cements. Z Kristallogr Sup 26:411-416

Mesbah A, François M, Cau-dit-Coumes C, Frizon F, Filinchuk Y, Leroux F, Ravaux J, Renaudin G (2011) Crystal structure of Kuzel's salt $3 \mathrm{CaO} \cdot \mathrm{Al}_{2} \mathrm{O}_{3} \cdot 1 / 2 \mathrm{CaSO}_{4} \cdot 1 / 2 \mathrm{CaCl}_{2} \cdot 11 \mathrm{H}_{2} \mathrm{O}$ determined by synchrotron powder diffraction. Cem Concr Res 41:504-509

Meyer KW, Neubauer J, Malovrh S (1998) New quality control with standardless clinker phase determination using the Rietveld refinement. ZKG Int 3:152-162

Mitchell LD, Margeson JC, Whitfield PS (2006) Quantitative Rietveld analysis of hydrated cementitious systems. Powder Diffr 21:111-113

Moller H (1995) Standardless quantitative phase analysis of Portland cement clinkers. World Cem 26:75-84 
Moller H (1998) Automatic profile investigation by the Rietveld method for standardless quantitative phase analysis. ZKG Int 1:40-50

Mondal P, Jeffery JW (1975) The crystal structure of tricalcium aluminate, $\mathrm{Ca}_{3} \mathrm{Al}_{2} \mathrm{O}_{6}$. Acta Crystallogr B31:689-697

Mumme WG, Hill RJ, Bushnell-Wye G, Segnit ER (1995) Rietveld crystal structure refinements, crystal chemistry and calculated powder diffraction data for the polymorphs of dicalcium silicate and related phases. Neues Jahrb Mineral Abh 169:35-68

Narmluk M, Nawa T (2011) Effect of fly ash on the kinetics of Portland cement hydration at different curing temperatures. Cem Concr Res 41:579-589

Navias AL (1925) Quantitative determination of the development of mullite in fired clays by an X-ray method. J Am Ceram Soc 8:296-302

Neubauer J, Kuzel HJ, Sieber R (1996) Rietveld quantitative XRD analysis of Portland cement: II. Quantification of synthetic and technical Portland cement clinkers. In: Proceedings of the $18^{\text {th }}$ International Conference on Cement Microscopy, 100-111, Houston, USA

Neubauer J, Mayerhofer W (2000) Solid solution series of ferrate and aluminate phases in OPC: Part I. The ferrate phase. In: Proceedings of the $22^{\text {nd }}$ International Conference on Cement Microscopy, 54-64, Montreal, Canada

O'Connor BH, Raven MD (1988) Application of the Rietveld refinement procedure in assaying powdered mixtures. Powder Diffr 3:2-6

Ojima K, Nishihata Y, Sawada A (1995) Structure of potassium sulfate at temperatures from 296 K down to 15K. Acta Crystallogr B51:287-293

Okada K, Ossaka J (1980) Structures of potassium sodium sulfate and tripotassium sodium disulfate. Acta Crystallogr B36:919-921

Onken H (1965) Verfeinerung der Kristallstruktur von Monticellit. Tsch Mineral Petrol Mitt 10:34-44

Paglia C, Wombacher F, Bohni H (2003) The influence of alkali-free and alkaline shotcrete accelerators within cement systems: Influence of the temperature on the sulfate attack mechanisms and damage. Cem Concr Res 33:387-395

Pajares I, De la Torre A, Martinez-Ramirez S, Puertas S, Blanco-Varela MT, Aranda MAG (2002) Quantitative analysis of mineralized white Portland clinkers: The structure of Fluorellestadite. Powder Diffr 17:281286

Palacios L, De la Torre AG, Bruque S, Garcia-Munoz JL, Garcia-Granda S, Sheptyakov D, Aranda MAG (2007) Crystal structures and in-situ formation study of Mayenite electrides. Inorg Chem 46:4167-4176

Paul M, Hornung D, Enders M, Schmidt R, (2004) Process monitoring in a cement plant: the combination of optimized preparation procedures for clinker and cement and Rietveld analysis. Cem Int 2:98-105

Pecharsky V, Zavalij P (2005) Fundamentals of Powder Diffraction and Structural Characterization of Materials. Springer, New York

Pelletier L, Winnefeld F, Lothenbach B (2010) The ternary system Portland cement-calcium sulphoaluminate clinker-anhydrite: Hydration mechanism and mortar properties. Cem Concr Comp 32:497-507

Petch HE (1961) The hydrogen positions in portlandite, $\mathrm{Ca}(\mathrm{OH})_{2}$, as indicated by the electron distribution. Acta Crystallogr 14:950-957

Peterson VK, Hunter BA, Ray A, Aldridge LP (2002) Rietveld refinement of neutron, synchrotron and combined powder diffraction data of cement clinker. Appl Phys A Suppl S1409-S1411

Peterson VK, Ray AS, Hunter BA (2006) A comparative study of Rietveld phase analysis of cement clinker using neutron, laboratory X-ray, and synchrotron data. Powder Diffr 21:12-18

Pollmann H (2006) Syntheses, properties and solid solution of ternary lamellar calcium aluminate hydroxi salts (AFm-phases) containing $\mathrm{SO}_{4}{ }^{2-}, \mathrm{CO}_{3}{ }^{2-}$ and $\mathrm{OH}^{-}$. Neues Jahrb Mineral Abh 182:173-181

Pollmann H (2007) Characterization of Different Water Contents of Ettringite and Kuzelite. In: Proceedings of $12^{\text {th }}$ International Congress on the Chemistry of Cement, Montreal, Canada

Poulsen SL, Kocaba V, Le Saout G, Jakobsen HJ, Scrivener KL, Skibsted J (2009) Improved quantification of alite and belite in anhydrous Portland cements by ${ }^{29} \mathrm{Si}$ MAS NMR: effects of paramagnetic ions. Solid State NMR 36:32-44

Pritula O, Smrcok L, Baumgartner B (2003) On reproducibility of Rietveld analysis of reference Portland cement clinkers. Powder Diffr 18:16-22

Pritula O, Smrcok L, Ivan J, Izdinsky K (2004b) X-ray quantitative phase analysis of residues of the reference Portland clinkers. Ceram Silik 48:34-39

Pritula O, Smrcok L, Tobbens DM, Langer V (2004a) X-ray and neutron Rietveld quantitative phase analysis of industrial Portland cement clinkers. Powder Diffr 19:232-239

Puertas F, García-Díaz I, Palacios M, Gazulla MF, Gómez MP, Orduña M (2010) Clinkers and cements obtained from raw mix containing ceramic waste as a raw material. Characterization, hydration and leaching studies. Cem Concr Comp 32:175-186 
Puertas F, Palacios M, Gil-Maroto A, Vazquez T (2009) Alkali-aggregate behaviour of alkali-activated slag mortars: Effect of aggregate type. Cem Concr Comp 31:277-284

Ramlochan T, Hooton RD (2011) Use of X-ray Diffraction to Investigate the Early Stiffening of Cement Pastes. In: Proceedings of $13^{\text {th }}$ International Congress on the Chemistry of Cement, 7 pages, Madrid, Spain

Rasmussen SE, Jorgensen JE, Lundtoft B (1996) Structures and phase transitions of $\mathrm{Na}_{2} \mathrm{SO}_{4}$. J Appl Crystallogr 29:42-47

Redhammer GJ, Tippelt G, Roth G, Amthauer G (2004) Structural variations in the brownmillerite series $\mathrm{Ca}_{2}\left(\mathrm{Fe}_{2-x} \mathrm{Al}_{x}\right) \mathrm{O}_{5}$ : Single-crystal X-ray diffraction at $25^{\circ} \mathrm{C}$ and high-temperature $\mathrm{X}$-ray powder diffraction $\left(25^{\circ} \mathrm{C} \leq T \leq 1000^{\circ} \mathrm{C}\right)$. Am Mineral 89:405-420

Renaudin G, Kubel F, Rivera JP, Francois M (1999) Structural phase transition and high temperature phase structure of Friedels salt, $3(\mathrm{CaO})\left(\mathrm{Al}_{2} \mathrm{O}_{3}\right)\left(\mathrm{CaCl}_{2}\right) \cdot 10\left(\mathrm{H}_{2} \mathrm{O}\right)$. Cem Concr Res 29:1937-1942

Richardson IG (2008) The calcium silicate hydrates. Cem Concr Res 38:137-158

Rietveld HM (1967) Line profiles of neutron powder-diffraction peaks for structure refinement. Acta Crystallogr 22:151-152

Rietveld HM (1969) A profile refinement method for nuclear and magnetic structures. J Appl Crystallogr 2:65-71

Rietveld HM (2010) The Rietveld method. Conference at the $10^{\text {th }}$ Spanish Summer School on the Rietveld Method. Castellon (Spain)

Rinaldi R, Sacerdoti M, Passaglia E (1990) Straetlingite: crystal structure, chemistry, and a reexamination of its polytype vertumnite. Eur J Mineral 2:841-849

Rodríguez-Carvajal J (1993) Recent advances in magnetic structure determination by neutron powder diffraction. Phys B 192:55-69

Roisnel T, Rodríguez-Carvajal J (2001) WinPLOTR: a Windows tool for powder diffraction patterns analysis. Mater Sci Forum 378-381:118-123

Rossler C, Eberhardt A, Kucerova H, Moser B (2008) Influence of hydration on the fluidity of normal Portland cement pastes. Cem Concr Res 38:897-906

Rousselot I, Taviot-Gueho C, Leroux F, Leone P, Palvadeau P, Besse JP (2002) Insights on the structural chemistry of hydrocalumite and hydrotalcite-like materials: investigation of the series $\mathrm{Ca}_{2} \mathrm{M}^{(3+)}$ $(\mathrm{OH})_{6} \mathrm{Cl} 2\left(\mathrm{H}_{2} \mathrm{O}\right)\left(\mathrm{M}^{(3+)}: \mathrm{Al}, \mathrm{Ga}, \mathrm{Fe}\right.$, and $\left.\mathrm{Sc}\right)$ by x-ray powder diffraction. J Solid State Chem 167:137-144

Saalfeld H, Depmeier W (1972) Silicon-free compounds with sodalite structure. Kristallogr Tech 7:229-233

Saalfeld H, Wedde M (1974) Refinement of the crystal structure of gibbsite, $\mathrm{Al}(\mathrm{OH})_{3}$. Kristallogr Kristallgeome Kristallphys Kristallchem 139:129-135

Saburi S, Kusachi I, Henmi C, Kawahara A, Henmi K, Kawada I (1976) Refinement of the structure of rankinite. Mineral J 8:240-246

Sacerdoti M, Passaglia E (1988) Hydrocalumite from Latium, Italy: its crystal structure and relationship with related synthetic phases. Neues Jahrb Mineral Monatsh 462-475

Sadanaga R, Tokonami M, Takeuchi Y (1962) The structure of mullite, $\left(\mathrm{Al}_{2} \mathrm{O}_{3}\right)_{2} \mathrm{SiO}_{2}$, and relationship with the structures of sillimanite and andalusite. Acta Crystallogr 15:65-68

Saint-Jean SJ, Hansen S (2005) Nonstoichiometry in chlorellestadite. Solid State Sci 7:97-102

Sasaki S, Fujino K, Takeuchi Y (1979) X-ray determination of electron-density distributions in oxides, MgO, $\mathrm{MnO}, \mathrm{CoO}$, and $\mathrm{NiO}$, and atomic scattering factors of their constituent atoms. Proc Japan Acad 55:43-48

Sawada H (1996) An electron density residual study of alpha-ferric oxide. Mater Res Bull 31(2):141-146

Scarlett NVY, Madsen IC (2006) Quantification of phases with partial or no known crystal structures. Powder Diffr 21:278-284

Scarlett NVY, Madsen IC, Cranswick LMD, Lwin T, Groleau E, Stephenson G, Aylmore M, Agron-Olshina N (2002) Outcomes of the International Union of Crystallography Commission on Powder Diffraction Round Robin on Quantitative Phase Analysis: samples 2, 3 and 4, synthetic bauxite, natural granodiorite and pharmaceuticals. J Appl Crystallogr 35:383-400

Scarlett NVY, Madsen IC, Manias C, Retallack D (2001) On-line X-ray diffraction for quantitative phase analysis: application in the Portland cement industry. Powder Diffr 16:71-80

Schreyer M, Guo L, Tjahjono M, Garland M (2011) Three approaches to total quantitative phase analysis of organic mixtures using an external standard. J Appl Crystallogr 44:17-24

Scrivener KL, Fullmann T, Gallucci E, Walenta G, Bermejo E (2004) Quantitative study of Portland cement hydration by X-ray diffraction/Rietveld analysis and independent methods. Cem Concr Res 34:15411547

Scrivener KL, Nonat A (2011) Hydration of cementitious materials, present and future. Cem Concr Res 41:651-665

Seufert S, Hesse C, Goetz-Neunhoeffer F, Neubauer J (2009a) Quantitative determination of anhydrite III from dehydrated gypsum by XRD. Cem Concr Res 39:936-941

Seufert S, Hesse C, Goetz-Neunhoeffer F, Neubauer J (2009b) Discrimination of bassanite and anhydrite III dehydrated from gypsum at different temperatures. Z Kristallogr Suppl 30:447-452 
Shanahan N, Zayed A (2007) Cement composition and sulfate attack: Part I. Cem Concr Res 37:618-623

Shin EJ, Seong BS, Lee CH, Huh MY (2002) Quantitative phase analysis of strongly textured alloy mixtures using neutron diffraction. J Appl Crystallogr 35:571-576

Skibsted J, Hall C (2008) Characterization of cement minerals, cements and their reaction products at the atomic and nano scale. Cem Concr Res 38:205-255

Skibsted J, Hall C, Jakobsen HJ (2002) Nuclear magnetic resonance spectroscopy and magnetic resonance imaging of cements and cementbased materials. In: Structure and Performance of Cements. 2nd Edition, Bensted J, Barnes P (ed), Spon Press, London, p 457-476

Smith DK (1992) Particle statistics and whole-pattern methods in quantitative X-ray powder diffraction analysis. Adv X-Ray Anal 35A:1-15

Smith DK, Johnson GG, Scheible A, Wims AM, Johnson JL, Ullrnann G (1987) Quantitative X-ray powder diffraction method using the full diffraction pattern. Powder Diffr 2:73-77

Smith DK, Leider HR (1968) Low-temperature thermal expansion of LiH, MgO and CaO. J Appl Cryst 1:246249

Snellings R, Mertens G, Cizer O, Elsen J (2010) Early age hydration and pozzolanic reaction in natural zeolite blended cements: Reaction kinetics and products by in situ synchrotron X-ray powder diffraction. Cem Concr Res 40:1704-1713

Snyder RL, Bish DL (1989) Quantitative analysis. Rev Mineral 20:101-144

Soleimanian V, Aghdaee SR (2008) Comparison methods of variance and line profile analysis for the evaluation of microstructures of materials. Powder Diffr 23:41-51

Speer D, Salje E (1986) Phase transitions in langbeinites I: Crystal chemistry and structures of K-double sulfates of the langbeinite type $\mathrm{M}_{2}{ }^{(2+)} \mathrm{K}_{2}\left(\mathrm{SO}_{4}\right)_{3}, \mathrm{M}^{(2+)}=\mathrm{Mg}, \mathrm{Ni}, \mathrm{Co}, \mathrm{Zn}, \mathrm{Ca}$. Phys Chem Mineral 13:17-24

Stanek T, Sulovsky P (2002) The influence of the alite polymorphism on the strength of the Portland cement. Cem Concr Res 32:1169-1175

Stark J (2011) Recent advances in the field of cement hydration and microstructure analysis. Cem Concr Res 41:666-678

Stark J, Möser B, Bellmann F (2008) Multi-method investigation of the ordinary Portland cement hydration. Cem Wapno Beton 13:57-65

Steele IM, Pluth JJ (1990) Crystal structure of synthetic yoshiokaite, a stuffed derivative of the tridymite structure. Am Mineral 75:1186-1191

Stutzman P (2005) Powder diffraction analysis of hydraulic cements: ASTM Rietveld round-robin results on precision. Powder Diffr 20:97-100

Stutzman P (2011) Direct Determination of Phases in Portland Cements by Quantitative X-Ray Powder Diffraction. NIST Technical Note 1692, 59 pages

Stutzman P, Leigh S (2002) Phase Composition Analysis of the NIST Reference Clinkers by Optical Microscopy and X-ray Powder Diffraction. NIST Technical Note 1441, 44 pages

Stutzman P, S. Leigh S, (2007) Phase analysis of hydraulic cements by X-ray powder diffraction: precision, bias, and qualification. J ASTM Int 4:1-11

Suherman PM, van Riessen A, O'Connor B, Li D, Bolton D, Fairhurst H (2002) Determination of amorphous phase levels in Portland cement clinker. Powder Diffr 17:178-185

Takeuchi Y, Nishi F, Maki I (1980) Crystal-chemical characterization of the $3(\mathrm{CaO}) \mathrm{Al}_{2} \mathrm{O}_{3}-\mathrm{Na}_{2} \mathrm{O}$ solid-solution series. Z Krist 152:259-307

Tang FJ, Gartner EM (1988) Influence of sulfate source on Portland cement hydration. Adv Cem Res 1:67-74

Taylor HFW (1989) Modification of the Bogue calculation. Adv Cem Res 2:73-77

Taylor HFW (1997) Cement Chemistry. Telford, London

Taylor JC, Aldridge LP (1993) Full-profile Rietveld quantitative XRD analysis of Portland cement: Standard XRD profiles for the major phase tricalcium silicate $\left(\mathrm{C}_{3} \mathrm{~S}: 3 \mathrm{CaO} . \mathrm{SiO}_{2}\right)$. Powder Diffr 8:138-144

Taylor JC, Hinczak I, Matulis CE (2000) Rietveld full-profile quantification of Portland cement clinker: The importance of including a full crystallography of the major phase polymorphs. Powder Diffr 15:7-18

Taylor JC, Matulis CE (1991) Absorption contrast effects in the quantitative XRD analysis of powders by full multi-phase profile refinement. J Appl Crystallogr 24:14-17

Taylor JC, Zhu R (1992) Simultaneous use of observed and calculated standard profiles in quantitative XRD analysis of minerals by the multiphase Rietveld method: the determination of pseudorutile in mineral sands products. Powder Diffr 7:152-161

Termkhajornkit P, Nawa T, Kurumisawa K (2006) Effect of water curing conditions on the hydration degree and compressive strengths of fly ash-cement paste. Cem Concr Comp 28:781-789

Thomas M, Fournier B, Folliard K, Ideker J, Shehata M (2006) Test methods for evaluating preventive measures for controlling expansion due to alkali-silica reaction in concrete. Cem Concr Res 36:1842-1856

Toby BH (2001) EXPGUI, a graphical user interface for GSAS. J Appl Crystallogr 34:210-213

Toby BH (2006) R factors in Rietveld analysis: How good is good enough? Powder Diffr 21:67-70

Toby BH (2007) A new approach for instruction in powder crystallography. Powder Diffr 22:83-84 
Toby BH (2010) Observations on online educational materials for powder diffraction crystallography software. J Appl Crystallogr 43:1271-1275

Toraya H, Hayashi S, Nakayasu T (1999) Quantitative phase analysis of $\alpha$ - and $\beta$-silicon nitrides. II. Round robins. J Appl Crystallogr 32:716-729

Torres SM, Kirk CA, Lysndale CJ, Swamy RN, Sharp JH (2004) Thaumasite-ettringite solid solutions in degraded mortars. Cem Concr Res 34:1297-1305

Walenta G, Fullmann T (2004) Advances in quantitative XRD analysis for clinker, cements, and cementitious additions. Powder Diffr 19:40-44

Wenk HR, Monteiro PJM, Kunz M, Chen K, Tamura N, Lutterotti L, Del Arroz J (2009) Preferred orientation of ettringite in concrete fractures. J Appl Crystallogr 42:429-432

Westphal T, Füllmann T, Pöllmann H (2009) Rietveld quantification of amorphous portions with an internal standard-Mathematical consequences of the experimental approach. Powder Diffr 24:239-243

Westphal T, Walenta G. Fullmann T, Gimenez M, Bermejo E, Scrivener K, Pollmann H (2002) Characterization of cementitious materials - Part III. Int Cem Rev July:47-51

Weyer HJ, Muller I, Scmitt B, Bosbach D, Putnis A (2005) Time-resolved monitoring of cement hydration: Influence of cellulose ethers on hydration kinetics. Nucl Instr Meth Phys Res B 238:102-106

Whitfield PS, Mitchell LD (2003) Quantitative Rietveld analysis of the amorphous content in cements and clinkers. J Mater Sci 38: 4415-4421

Whitfield PS, Mitchell LD (2009) The effects of particle statistics on Rietveld analysis of cement. Z Kristallogr Suppl 30:53-59

Will G, Bellotto M, Parrish W, Hart M (1988) Crystal structures of quartz and magnesium germanate by profile analysis of synchrotron-radiation high-resolution powder data. J Appl Crystallogr 21:182-191

Wistuba S, Stephan D, Raudaschl-Sieber G, Plank J (2007) Hydration and hydration products of two-phase Portland cement clinker doped with $\mathrm{Na}_{2} \mathrm{O}$. Adv Cem Res 19:125-131

Yamaguchi G, Suzuki K (1967) Structural analysis of merwinite. J Cer Soc Japan 75:220-229

Young RA (ed) (1993) The Rietveld Method. International Union of Crystallography monographs on Crystallography. Oxford University Press, Oxford

Zevin LS, Kimmel G (1995) Quantitative X-Ray Diffractometry. Springer-Verlag, New York

Zotzl M, Pollmann H (2006) Stability and properties of brownmillerites $\mathrm{Ca}_{2}(\mathrm{Al}, \mathrm{Mn}, \mathrm{Fe})_{2} \mathrm{O}_{5}$ and perovskites $\mathrm{Ca}(\mathrm{Mn}, \mathrm{Fe}) \mathrm{O}_{3-x}$ in the system $\mathrm{Ca}_{2} \mathrm{Fe}_{2} \mathrm{O}_{5}-{ }^{-} \mathrm{Ca}_{2} \mathrm{Mn}_{2} \mathrm{O}_{5}{ }^{\prime}-{ }^{-"} \mathrm{Ca}_{2} \mathrm{Al}_{2} \mathrm{O}_{5}$ ". J Am Ceram Soc 89:3491-3497 